Revista Aportes para la Integración Latinoamericana Año XXV, N 40/Junio 2019, ISSN 2468-9912

Pasquale Cerbone Análisis de la inclusión de la Comunidad Andina en el desarrollo del proyecto "Cinturón y Ruta" para el desarrollo de la infraestructura ferroviaria DOI: https://doi.org/10.24215/24689912e018

\title{
ANÁlisis de LA INCLUSIÓN DE LA COMUNIDAD ANDINA EN EL PROYECTO "CINTURÓN Y RUTA" PARA EL DESARROLLO DE LA INFRAESTRUCTURA FERROVIARIA
}

\section{ANALYSIS OF THE INCLUSION OF THE COMUNIDAD ANDINA IN "ONE BELT ONE ROAD" PROJECT: FOR THE DEVELOPMENT OF RAILWAY INFRAESTRUCTURE}

Pasquale Cerbone

\begin{abstract}
RESUMEN
El presente artículo proyecta la inclusión de los países miembros de la Comunidad Andina en una eventual extensión del plan chino "Cinturón y Ruta" en la región suramericana; esto con el fin de responder a la exigencia de mejora de la infraestructura para el transporte ferroviario entre los países miembros de la Comunidad Andina, con el fin de identificar los posibles efectos que esto puede conllevar para el comercio internacional, la integración y la visión geopolítica de los países que conforman la organización. La metodología propuesta en este artículo, en cuanto a la evaluación de la factibilidad de la propuesta, se basa en una amplia revisión bibliográfica con miras a la identificación de elementos que posteriormente se relacionarán al interno de una matriz FODA de tipo ponderada. Dichos elementos atienen a las relaciones internas entre los países de la organización subregional, y de los mismos con el socio chino. Las conclusiones muestran que tanto para el comercio internacional como para la integración regional el proyecto no aportaría con particulares ventajas para los miembros de la Comunidad Andina; sin embargo, podría modificar la proyección geopolítica que ellos mantienen tanto a nivel regional como global.
\end{abstract}

\section{PALABRAS CLAVE}

Integración regional, China, Comunidad Andina, Cinturón y Ruta

\begin{abstract}
This article projects the inclusion of the member countries of the Comunidad Andina in an eventual extension of the Chinese plan "One Belt One Road" in the region of South America; in order to respond to the need to improve infrastructure for rail transport between CAN member countries. The aim of this article is identify possible effects that this can entail for the international trade, the integration and the geopolitical vision of the countries that constitute the organization. The methodology proposed in this article, to evaluate the feasibility of the proposal, is based on a wide bibliographical revision to identify the elements that will later be related to the internal of a SWOT matrix of weighted type. Such elements keep relation with the internal relationships among the members of the sub regional organization and among such with the Chinese partner. The conclusions show that both about the international trade and the regional integration the project would not produces particular advantages; nonetheless, it could modify the geopolitical projection that those country keep both at regional and global level.
\end{abstract}

\section{KEY WORDS}

Regional integration, China, Comunidad Andina, One Belt One Road 


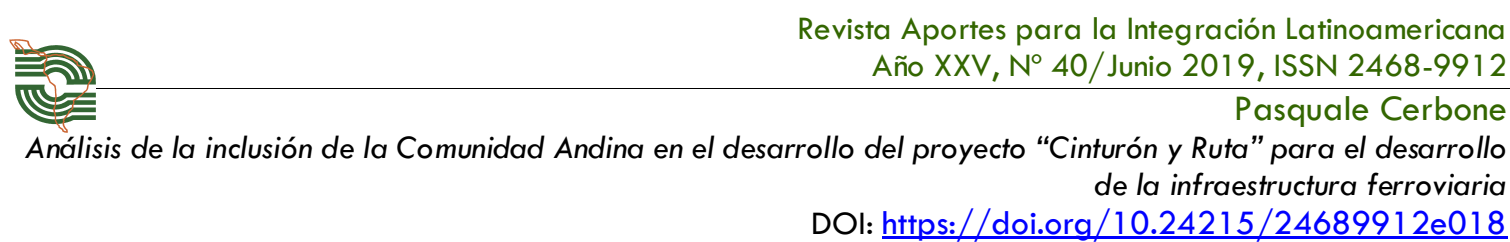

\section{INTRODUCCIÓN}

En el año 2000 en la ciudad de Brasilia, se establecieron las bases de un singular proyecto de integración para la región de América del Sur: la Integración de la Infraestructura Regional Suramericana. Este sistema planteaba un proyecto de integración que no se generase desde una perspectiva puramente económica o política, sino que empezase desde una de las comunes necesidades de la región suramericana: invertir en la infraestructura vial "bajo una concepción regional del espacio suramericano", así como lo afirmó en el 2005 Enrique García, ex Presidente Ejecutivo de la Corporación Andina de Fomento (CAF, 2005). Esta nueva forma de pensar en la integración habría permitido superar las dificultades históricas de este proceso, como el fuerte presidencialismo que caracteriza los gobiernos de la región, reforzado por las distancias ideológicas entre los diferentes mandatarios (Malamud, 2015). Además, muchas organizaciones internacionales acogieron favorablemente el diseño previsto por la Iniciativa para la Integración de la Infraestructura Regional Suramericana (IIRSA); entre ellas el FMI (2017) recomendó seguir con el camino de mejora de la infraestructura a nivel regional, considerando este factor como necesario para el crecimiento económico de América del sur; también la CEPAL (2014), años atrás, y el CAF (2017) proponían invertir, respectivamente, el $6,2 \%$ y el $5 \%$ del PIB nacional en proyectos infraestructurales, reconociendo su valor estratégico.

No obstante, pese al carácter práctico de la idea mencionada y a los esfuerzos obrados por los gobiernos de la región en formular proyectos, sus efectos fueron escasos: faltó crear un orden de prioridades entre las diferentes propuestas avanzadas y minimizar el impacto negativo que la burocracia intrincada de estos países habría tenido sobre su realización (Ochoa, 2018). Por eso, cuando en el periodo de bonanza económica, que envuelven a la región entre el 2009 y el 2015 (FMI, 2018) se realizaron proyectos de infraestructura, estos cayeron dentro de una visión de desarrollo estatal mas no regional, presentando resultados insatisfactorios dentro de una perspectiva integracionista. Por ejemplo, uno de los planes más controversiales que se generó, en relación a la implementación de nueva infraestructura de transporte, fue la construcción de un corredor bioceánico. De hecho, en la visión de los gobiernos de la región, el conectar los países con salida al océano Pacífico con Brasil habría permitido a la región comercializar más 


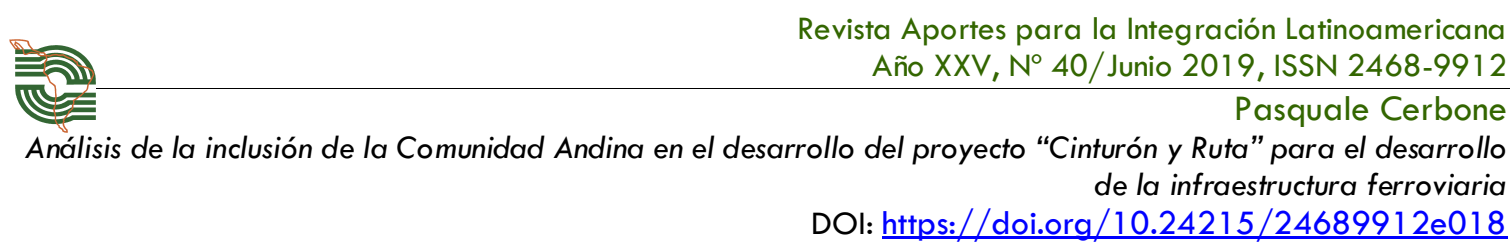

fácilmente tanto con los países europeos que con los asiáticos, superando la mediación logística del canal de Panamá y abaratando el precio de los bienes de exportación (Graziani Mora, 2017). Entre los diferentes corredores identificados, el que mayormente se acercó a su realización fue el corredor multimodal "Manta-Manaos"; debido a la gran disponibilidad de los expresidentes de Ecuador y Brasil (Rafael Correa y Luiz Lula da Silva) en garantizar los USD 800 millones necesarios para su construcción (ALADI, 2008). Sin embargo, este proyecto presentaba diferentes aspectos críticos que impidieron su realización: Durán (2013) argumenta que las hipótesis de fortalecimiento del comercio intrarregional y de desarrollo de las regiones periféricas de la Amazonía involucradas en el plan, junto con el abaratamiento de los costos de las mercancías, ambas ideas sobre las cuales se fundamenta el proyecto del corredor, constituían hipótesis improbables. Inclusive, Wilson y Bayon (2017) describen al plan como la "materialización de un sueño" con valor político mas no económico, en cuanto se basa en la ilusión de poder conciliar elementos opuestos, como la edificación de una infraestructura ingente con la necesidad de mantener intacta la región amazónica, o también el de generar crecimiento económico para Ecuador, cuando en realidad, según la misma fuente, Brasil habría sido el país que mayormente habría podido aprovechar de esa infraestructura. Además, se pretendía que el proyecto generase una oportunidad de desarrollo global para las poblaciones involucradas, sin que hubiesen consecuencias sobre las comunidades que se encuentran en aislamiento voluntario en la selva amazónica (Bonilla, 2012).

Por último, se puede añadir que si el plan hubiese tenido el éxito esperado, debido a su estructura geográfica, seguramente no habría generado desarrollo para toda la región y menos aún reforzado la integración entre los países de América del sur, al involucrar básicamente solo dos de los doce países que conforman a la región considerada.

Por tanto, actualmente se volvió a pensar en formas alternativas de integración a partir de la infraestructura, que superasen las debilidades del proyecto mencionado. Una posibilidad puede ser representada por la creación de infraestructura en las organizaciones subregionales. En este sentido, como se verá más adelante y por su estabilidad, la CAN puede considerarse como una opción viable, sobre todo gracias a las 


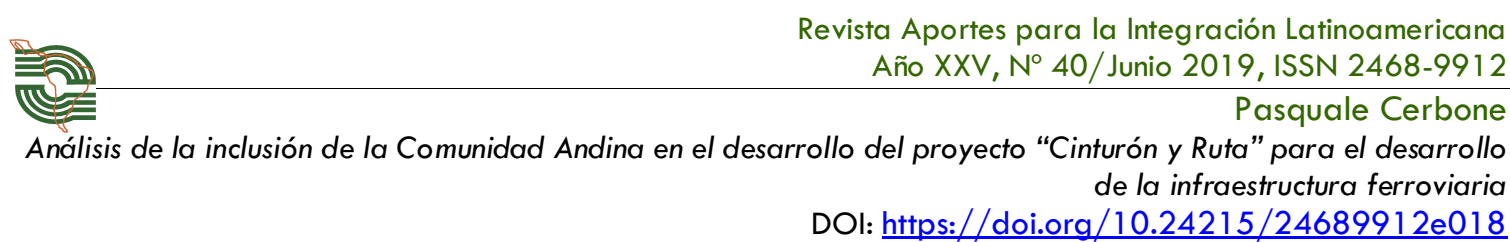

buenas relaciones que sus países miembros mantienen con China, y a la propuesta de este de abarcar al interno del proyecto "Cinturón y Ruta" a los países de América Latina.

\section{EL PLAN CINTURÓN Y RUTA: UNA OCASIÓN PARA AMÉRICA DEL SUR}

El aislamiento geográfico de América del Sur no favorece su inclusión en los planes geopolíticos globales de sus socios tradicionales, los países occidentales, quienes por diferentes razones se encuentran concentrados en la región de Oriente Medio y en las disputas con Rusia y China. Además, la falta de una integración efectiva de la región sustrae parcialmente a los países de esta el poder contractual necesario para tomar las riendas de su proceder político y económico, lo que provoca una pérdida de valor en el protagonismo geopolítico que posee la región suramericana, bajo diferentes aspectos (Malamud, 2015). Pese a eso, según Detsch (2018), como consecuencia del prevalecer de gobiernos con tendencia socialista en la década pasada, Rusia y particularmente China han podido incursionar y posicionarse en la región considerada de forma que, actualmente, ambos países están cubriendo el vacío dejado por los socios tradicionales, en cuanto a inversión en proyectos estratégicos para el desarrollo (Serbin, 2018).

En cuanto a China, cabe mencionar que en el 2013 lanzó una propuesta que de realizarse constituirá el emblema de este siglo en cuanto a fortalecimiento de la integración global. El megaproyecto, denominado "Cinturón y Ruta" (CYR), puede modificar radicalmente la percepción que existe por parte del mundo sobre el dragón asiático. De hecho, para que eso ocurra China ha creado instituciones financieras capaces de remplazar las que fueron creadas en la conferencia de Bretton Woods: por ejemplo, si se realiza el proyecto chino, el Banco Asiático de Inversiones en Infraestructura podría sustituir progresivamente el papel jugado por el Banco Mundial en proyectos de desarrollo (Pastrana Buelvas \& Castro, 2018).

Desde el punto de vista financiero, el proyecto CYR consiste en el mayor plan de inversión en infraestructuras que haya sido realizado en la historia; tanto por su dimensión económica como por la geográfica, misma que abarca una amplísima porción del comercio global. 


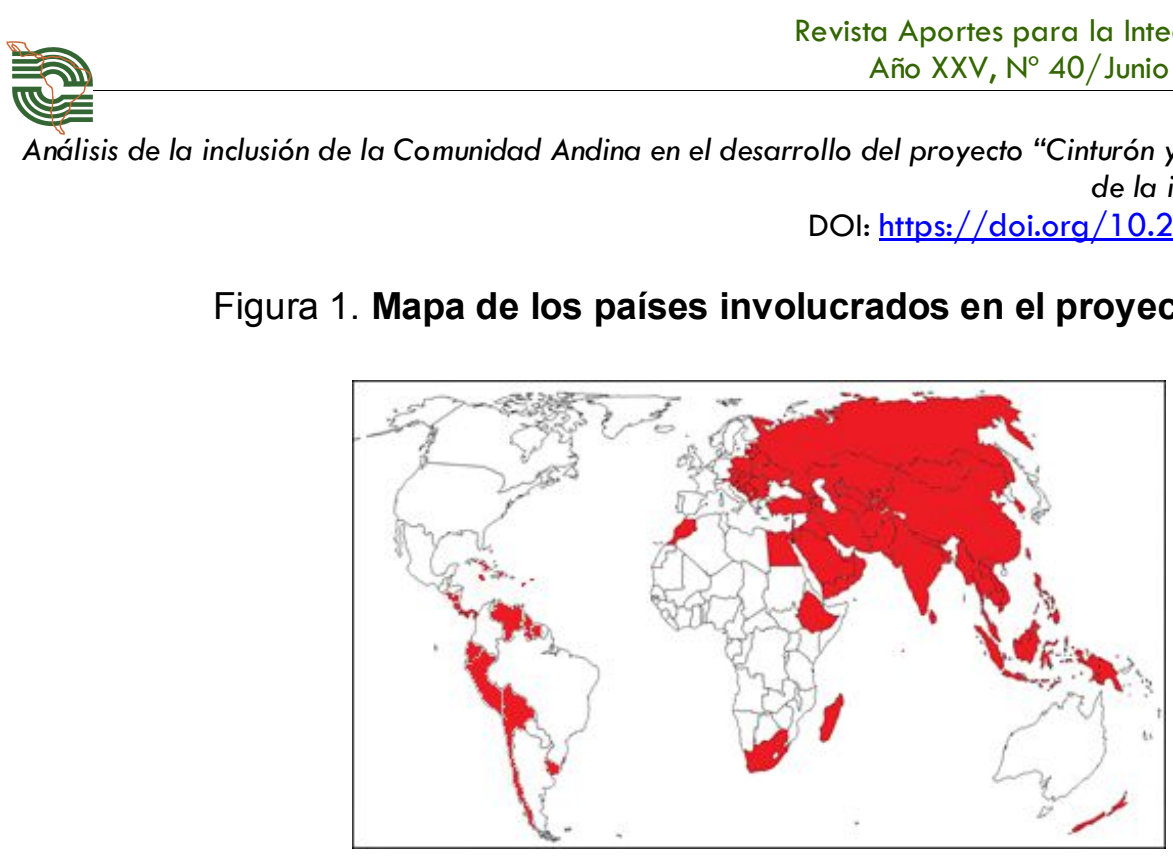

Fuente: Elaboración propia con datos de China Trade Research (HKTDC, 2019).

De tal forma que China ha creado un fondo de USD 40 mil millones, para proyectos con miras a la construcción de infraestructura para el transporte. Además, ha abierto un fondo para la participación multilateral de sujetos públicos y privados en proyectos de infraestructura para la provisión energética (Indeo, 2017).

Desde el punto de vista geográfico, el proyecto CYR abarca dos rutas: una terrestre y otra marítima, diseñadas para conectar de forma más eficiente a China con Europa y África.

Cabe mencionar que el proyecto se basa sobre cinco pilares que se presentan como concordantes con la política exterior china de la cual se hablará más adelante, que son: i) la coordinación política; ii) la conectividad; iii) mayor facilitación del comercio; iv) mayor integración financiera; v) cooperación social (Amighini, 2017). Estos criterios favorecen el crecimiento de la economía china, a través de la posibilidad de alcanzar una mayor expansión en el mercado global; sin embargo, no dejan de reflejar la necesidad creciente de integración en la economía global de la cual necesitan muchas regiones del mundo para su desarrollo, entre las cuales se encuentra América del Sur (Rodríguez, 2017).

Además, como afirma el Dr. Chan (2016), el proyecto CYR se inscribe al interno de una estrategia más amplia, que viene definida en la conferencia citada como "diplomacia del ferrocarril", a través de la cual China quiere conectar a los países del mundo, mediante la más amplia red de ferrocarriles de la historia. Particularmente, América se conectaría a Asia mediante tuneles submarinos a través del estrecho de Bering, y la linea de 


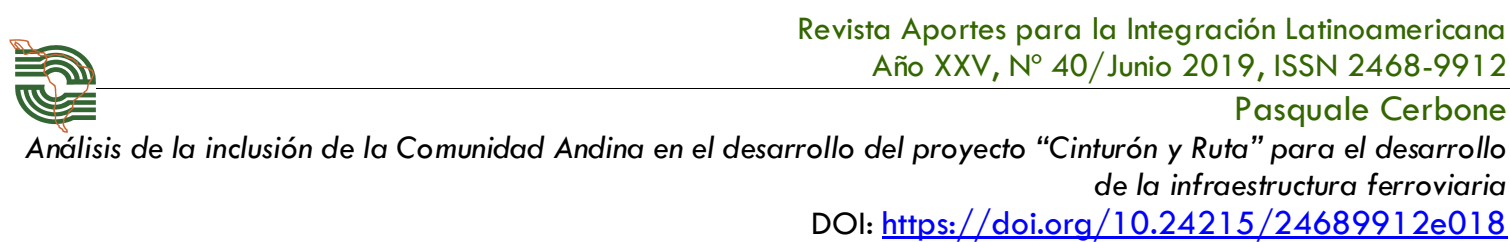

ferrocarriles que la atravesería pasaría también en América del Sur, cruzando los países de la CAN y llegando hasta la Patagonia.

De hecho, en el 2014, los jefes de Estado y gobierno de los países de América Latina, se encontraron con el presidente chino en la ciudad de Brasilia definiendo un sistema de "cooperación integral" a través de la constitución del Foro China-CELAC (Ministerio de Relaciones Exteriores de la República Popular de China, 2019). Cabe aclar, que esto ha sido posible, como enuncia el "Documento sobre la Política de China Hacia América Latina y el Caribe", en cuanto China no reconoce en los países de América Latina ninguna hostilidad en cuanto a la realización de sus planes de política interna y exterior. Particularmente, en cuanto a los países miembros de la CAN se puede mencionar que Bolivia y Ecuador ya firmaron memorandos de entendimiento con el gobierno Chino sobre la cooperación en el ámbito del proyecto CYR (Ministerio de Relaciones Exteriores del Estado Plurinacional de Bolivia, 2018) (Ministerio de Relaciones Exteriores y Movilidad Humana de Ecuador, 2018); en cambio Perú ha demostrado con acciones diplomática su interés sobre el proyecto (Ministerio de Relaciones Exteriores del Estado Peruano, 2019). Debido a esto, en los próximos apartados se analizará la posibilidad de implementar una red de ferrocarriles que interconecte los países de la CAN, como efecto de la eventual participación de los mismos al mega proyecto chino, asumiendo inicialmente, la posibilidad que China quiera realmente desarrollar dicho proyecto en el ambito de una estrategia de "ganar-ganar" y dejando a las futuras investigaciones la posibilidad de operar una crítica más profunda sobre las reales intenciones del gigante asiático, debido a que no existen todavía, en el contexto de América Latina, suficientes elementos útiles para tomar una posición favorable o desfavorable a la realización del proyecto.

\section{2. Participar en el proyecto "CYR" como medio para la dotación de una línea eficiente de ferrocarriles: una propuesta para la región andina}

La ruta terrestre del plan CYR prevé para los países que quieran adherir en el proyecto, la instalación de una amplísima red de ferrocarriles. En muchos países, sobre todo en los que ya poseían esta infraestructura de base, se ha proyectado la posibilidad de implementar o ampliar el funcionamiento de trenes de alta velocidad (Xu, Shen, Jiang, \& Jin, 2017). 


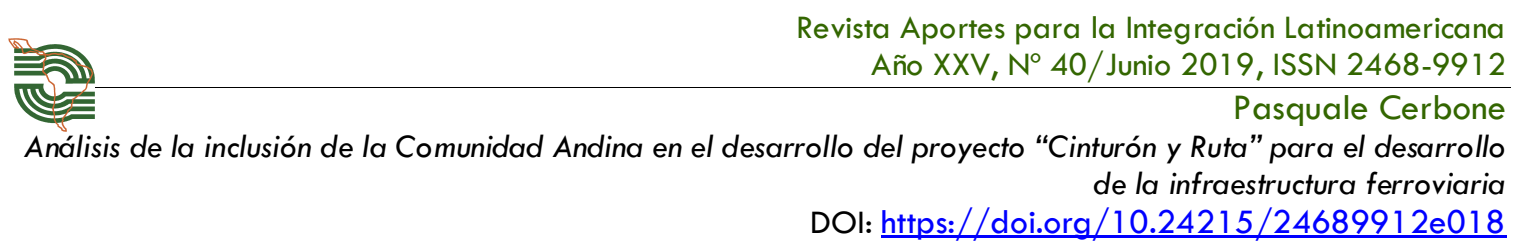

La inversión para este tipo de infraestructura se basa sobre todo en la idea optimista de poder aportar al desarrollo en diferentes sectores de la economía de un país: se puede aumentar la ocupación y el comercio, como está confirmado por el amplio uso que se está haciendo en China de este tipo de infraestructura vial (Xu, Zhou, Yang, \& Li, 2018). De hecho, Dai, Xu, y Wang (2018) afirman que la implementación de esta infraestructura ha permitido una reasignación eficiente de los recursos estatales a los gobiemos locales, lo que ha facilitado la formación de aglomerados industriales que han dinamizado la economía, generando nuevas plazas de trabajo. Además, como ha sido comprobado por Mi (2018), esta modalidad de transporte ayuda el crecimiento de la economía a través de la reducción de los tiempos de viaje y permite una mayor conectividad entre las ciudades o las regiones de un país.

Inclusive, otros estudios, demuestran como los trenes de alta velocidad ayudan a sectores económicos como el turístico, aumentando el flujo endógeno de viajeros, al ofertar una modalidad de transporte más económica y ecológica que el transporte aéreo (CastilloManzano, Castro-Nuño, López-Valpuesta, Pedregal-Tercero, \& Garrido-Michó, 2018). De hecho, se puede utilizar el tren de alta velocidad con el fin de disminuir la contaminación atmosférica: hace alrededor de una década, de Rus y Nombela (2007) demostraron que para viajes regionales, el tren de alta velocidad ofrece grandes ventajas en términos de reducción de la contaminación, frente al uso de aviones.

No obstante la construcción instauración de una línea de ferrocarril, sobre todo si se emplean trenes de alta velocidad, conlleva también aspectos controversiales, como la necesidad de planificar la infraestructura para que no exista una desproporción con la demanda. A este propósito, Beria, Grimaldi, Albalate, y Bel (2018) afirman que sobre la mencionada desproporción pueden influir factores diferentes de la planificación, como los problemas estructurales del sistema administrativo de un país. Para eso es necesario un sistema legal y burocrático sólido pero "ligero", capaz de planificar y realizar oportunamente proyectos de esta magnitud; lo que representaría un gran reto para los países de la región suramericana si se implementase esta propuesta. Pese a las dificultades mencionadas, la dotación de una red de ferrocarriles a nivel regional en América del Sur parece ser una prioridad ya identificada por algunos organismos 


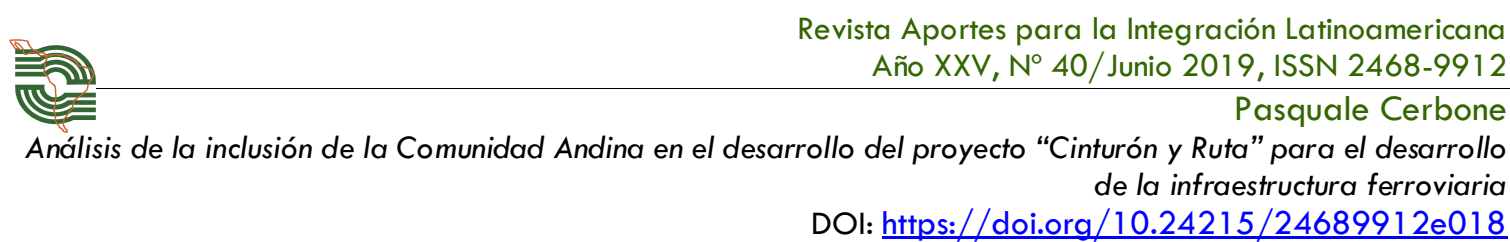

multilaterales, entre los cuales se encuentra la UNASUR: en el 2017 la organización presentó un proyecto basado en el concepto de "corredores de integración", que se enfoca en el diseño de posibles rutas ferroviarias entre los países de la región (UNASURCOSIPLAN, 2017). Por eso, si se decidiera implementar una tecnología como la de la alta velocidad, la región podría aprovechar esa serie de ventajas anteriormente mencionadas, de las cuales necesita para su crecimiento económico. Para este fin, los países suramericanos podrían atraer la inversión china en la región, mediante el diseño de un plan de participación multilateral en el CYR diseñado según la lógica del "ganar-ganar". No obstante, debido a la débil "arquitectura institucional" de la región lo que dificulta la coordinación entre los países de la misma (CEPAL, 2017) en este artículo se propone la idea de empezar con la participación de un menor número de Estados, específicamente, con los países que conforman la Comunidad Andina (CAN). De hecho, esta organización constituye uno de ejemplos de integración a nivel de la región más longevos, lo que ha consolidado la práctica del dialogo entre las partes, lo que es una condición necesaria para la formulación de planes como el que se propone. Además, pese a constituir una organización subregional, la CAN presenta una vocación regional, proponiéndose alcanzar un desarrollo integral "mediante la integración andina, suramericana y latinoamericana" (Comunidad Andina, 2018).

Por tanto, la pregunta de base de esta investigación es cuáles serían las implicaciones de la eventual participación en el proyecto CYR por parte de los miembros de la CAN.

\section{ELEMENTOS FAVORABLES PARA LA PRESENTACIÓN DE LA PROPUESTA}

III. 1. La existencia de una integración fuerte entre los países miembros de la CAN y de buenas relaciones comerciales de los mismos con China

En 1969, a través de la firma del Pacto Andino, los países de Bolivia, Chile, Colombia, Ecuador y Perú, crearon una forma de integración que desembocó, a través del Protocolo de Trujillo de 1996, en la constitución de la Comunidad Andina.

El proceso de integración de la CAN se fundamenta sobre la existencia de instituciones autónomas, que constituyen el Sistema Andino de Integración (Comunidad Andina, 2018). En sus inicios, como se mencionó anteriormente, la CAN estaba integrada también por 
Chile, que salió de la organización en el 1976, y por un periodo vio la participación de Venezuela, que ha integrado la CAN desde el 1973 hasta el 2006.

A través de este sistema, el proceso de integración entre las partes ha crecido progresivamente. De hecho, desde el punto de vista específicamente comercial, según datos recaudados por el Center for International Development at Harvard University (2016), los países miembros de esta organización internacional resultan ser socios comerciales mutuamente importantes.

La tabla a continuación muestra la situación comercial entre los miembros de la organización, identificando la posición que el mercado de la CAN mantiene en calidad de socio comercial para cada uno de ellos. Se hará referencia a eso, tanto en tema de importaciones como en exportaciones.

Tabla 1. Importaciones entre miembros de la CAN; porcentaje sobre el total de las importaciones, y posición de la CAN como socio comercial en cuanto a importaciones durante el 2016

\begin{tabular}{|c|c|c|c|c|c|c|}
\hline \multicolumn{7}{|c|}{ IMPORTACIONES ENTRE LOS MIEMBROS DE LA CAN (2016) } \\
\hline & BOLIVIA & COLOMBIA & ECUADOR & PERÚ & TOTAL & $\begin{array}{c}\text { POSICIÓN CAN, COMO SOCIO } \\
\text { COMERCIAL }\end{array}$ \\
\hline BOLIVIA & & $1.91 \%$ & $0.47 \%$ & $6.53 \%$ & $8.91 \%$ & 5 \\
\hline COLOMBIA & $1.25 \%$ & 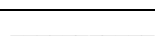 & $1.80 \%$ & $1.55 \%$ & $4.6 \%$ & 5 \\
\hline ECUADOR & $1.33 \%$ & $7.79 \%$ & - & $3.94 \%$ & $13.06 \%$ & 2 \\
\hline PERÚ & $1.13 \%$ & $3.20 \%$ & $2.90 \%$ & 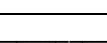 & $7.23 \%$ & 3 \\
\hline
\end{tabular}

Fuente: Elaboración propia con datos de Center for International Development at Harvard University (2016)

Tabla 2. Exportaciones entre miembros de la CAN; porcentaje sobre el total de las exportaciones, y posición de la CAN como socio comercial en cuanto a exportaciones durante el 2016 
Revista Aportes para la Integración Latinoamericana Año XXV, N 40/Junio 2019, ISSN 2468-9912

Pasquale Cerbone

Análisis de la inclusión de la Comunidad Andina en el desarrollo del proyecto "Cinturón y Ruta" para el desarrollo de la infraestructura ferroviaria DOI: https://doi.org/10.24215/24689912e018

\begin{tabular}{|c|c|c|c|c|c|c|}
\hline \multicolumn{7}{|c|}{ EXPORTACIONES ENTRE LOS MIEMBROS DE LA CAN (2016) } \\
\hline & BOLIVIA & COLOMBIA & ECUADOR & PERÚ & TOTAL & $\begin{array}{c}\text { POSICIÓN CAN, COMO SOCIO } \\
\text { COMERCIAL }\end{array}$ \\
\hline BOLIVIA & 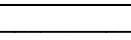 & $8.18 \%$ & $3.13 \%$ & $5.81 \%$ & $17.12 \%$ & 2 \\
\hline COLOMBIA & $0.44 \%$ & 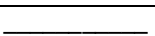 & $3.28 \%$ & $2.95 \%$ & $6.67 \%$ & 2 \\
\hline ECUADOR & $0.22 \%$ & $4.25 \%$ & 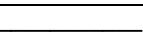 & $5.38 \%$ & $9.85 \%$ & 2 \\
\hline PERÚ & $1.63 \%$ & $1.98 \%$ & $1.81 \%$ & 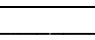 & $5.42 \%$ & 2 \\
\hline
\end{tabular}

Fuente: Elaboración propia con datos de Center for International Development at Harvard

University (2016)

Como se puede observar, la CAN constituye para cada uno de sus miembros un espacio muy importante para la economía nacional considerando que, particularmente en cuanto a las exportaciones, el área comercial constituida por la organización representa el segundo mercado más importante para todos los integrantes de la organización; mientras que en tema de importaciones la misma área tiene una importancia que varía entre la segunda y la quinta posición. Esto último es obvio, si se considera la necesidad de los países de la región de importar productos altamente elaborados, frente al nivel mínimo de producción de los mismos por parte de los países de la CAN, que de hecho, son principalmente productores de materias primas. Eso conlleva que la importación de los productos más necesarios ocurra afuera del área de mercado de la CAN.

Por esta razón, las relaciones comerciales con China son favorables. La tabla a continuación nos permite observar la magnitud de las mismas, pudiéndose concluir que para cada uno de los miembros de la CAN los productos chinos están entre los más importados.

Tabla 3.: Importaciones desde China, porcentaje sobre el total de las importaciones, y posición de China como socio comercial en cuanto a importaciones durante el 
DOI: https://doi.org/10.24215/24689912e018

\begin{tabular}{|l|c|c|c|}
\hline \multicolumn{3}{|c|}{ IMPORTACIONES DE LOS PAISES MIEMBROS DE LA CAN DESDE CHINA (2016) } \\
\hline & $\begin{array}{c}\text { IMPORTACIONES DESDE CHINA EN } \\
\text { MILES DE MILLONES DE USD }\end{array}$ & $\begin{array}{c}\text { PORCENTAJE PARTICIPACIÓN } \\
\text { IMPORTACIÓN DESDE CHINA }\end{array}$ & $\begin{array}{c}\text { POSICIÓN DE CHINA COMO SOCIO } \\
\text { COMERCIAL }\end{array}$ \\
\hline BOLIVIA & 1.60 & $18.31 \%$ & $\mathbf{1}$ \\
\hline COLOMBIA & 7.35 & $16.38 \%$ & $\mathbf{2}$ \\
\hline ECUADOR & 2.94 & $18.17 \%$ & $\mathbf{1}$ \\
\hline PERÚ & 7.83 & $22.18 \%$ & \\
\hline
\end{tabular}

Fuente: Elaboración propia con datos de Center for International Development at Harvard University (2016)

A través de los datos brindados por el Center for International Development at Harvard University (2016) se observa también que en conjunto la CAN representa el segundo importador de productos chinos en América del Sur, con un total de USD 19.72 mil millones en el 2016, superado solo por Brasil que importó un total de USD 22.1 mil millones en el mismo año. Se deduce que las relaciones comerciales con el socio asiático chino se presentan como un elemento favorable para el diseño de un proyecto que apunte a una mayor fluidez comercial entre las partes.

También, es posible observar que en el tema de inversión extranjera China representa un socio fundamental tanto para Ecuador como para que Bolivia, mientras que para Colombia y Perú la inversión china no ocupa todavía una posición relevante sobre el total de inversiones directas extranjeras. Sin embargo, como demuestra la tabla a continuación, el dato más importante es que en todos los países considerados hecha excepción por Bolivia (del cual no existe acceso directo a los datos investigados) la inversión china ha tenido un ritmo creciente; lo que demuestra un interés progresivo del gigante asiático en los países miembros de la CAN.

Tabla 4. Total IDE; IDE de China; porcentaje sobre el total de IDE de la inversión china; posición de China como socio estratégico en inversiones en el año 2017 
Revista Aportes para la Integración Latinoamericana Año XXV, N 40 / Junio 2019, ISSN 2468-9912

Pasquale Cerbone

Análisis de la inclusión de la Comunidad Andina en el desarrollo del proyecto "Cinturón y Ruta" para el desarrollo de la infraestructura ferroviaria

DOI: https://doi.org/10.24215/24689912e018

\begin{tabular}{|c|c|c|c|c|c|}
\hline \multicolumn{7}{|c|}{ IDE EN MILLONES DE USD EN LOS PAÍSES DE LA CAN (2017) } \\
\hline & TOTAL IDE & $\begin{array}{c}\text { IDE DE } \\
\text { CHINA }\end{array}$ & $\begin{array}{c}\text { PORCENTAJE } \\
\text { SOBRE EL TOTAL }\end{array}$ & $\begin{array}{c}\text { POSICIÓN DE CHINA COMO } \\
\text { SOCIO EN INVERSIONES }\end{array}$ & $\begin{array}{c}\text { INCREMENTO } \\
\text { DESDE EL 2002 }\end{array}$ \\
\hline BOLIVIA & $\begin{array}{c}\text { (datos no } \\
\text { disponibles) }\end{array}$ & 712,6 & (dato no disponible) & 25 \\
\hline COLOMBIA & 13.924 & 32,8 & $0,24 \%$ & 1 \\
\hline ECUADOR & 611,978 & 84,677 & $13,84 \%$ & $\mathbf{+ 5 3 6 6}$ \\
\hline PERÚ & $25.684,2$ & 212,17 & $0,82 \%$ & $\mathbf{+ 4 3 7 \%}$ \\
\hline
\end{tabular}

Fuentes: Elaboración propia con datos de: Banco Central del Ecuador (2018), Banco de la República - Colombia (2018), Proinversión (2018), Padilla (2018).

Pese al bajo porcentaje sobre el total de la IDE que reciben por parte de China los miembros de la CAN, mirando al incremento de esta se puede afirmar que existe una conveniencia para los miembros de la CAN en reforzar los lazos con China. De hecho, como se dijo anteriormente, el proyecto CYR tiene entre sus fines el de crear una facilitación del comercio internacional y dado que tanto los países de la CAN que China se presentan como socios mutuamente relevantes, podría concluirse que existe una conveniencia para concretar una extensión de dicho proyecto entre los actores analizados en este artículo.

III. 2. La existencia de una infraestructura ferroviaria previa y de elementos favorables para su mejora en los países los miembros de la CAN

En los cuatro países miembros de la CAN, se empezó la construcción de una red ferroviaria a finales del siglo XIX.

La tabla a continuación, muestra las principales características del sistema ferroviario de cada uno de los miembros de la CAN.

Tabla 5. Informaciones sobre la red ferroviaria de los países miembros de la CAN

\begin{tabular}{|c|c|c|c|c|c|}
\hline PAÍS & $\begin{array}{c}\text { AÑO DE INICIO } \\
\text { DE LA } \\
\text { CONSTRUCCIÓN }\end{array}$ & $\begin{array}{c}\text { LONGITUD } \\
\text { TOTAL }\end{array}$ & $\begin{array}{c}\text { TIPO DE EMPRESAS QUE } \\
\text { GESTIONAN LA RED }\end{array}$ & $\begin{array}{c}\text { TIPO DE } \\
\text { CARGA }\end{array}$ & $\begin{array}{c}\text { CONEXIONES } \\
\text { INTERNACIONALES O } \\
\text { ESTRATÉGICAS }\end{array}$ \\
\hline BOLIVIA & 1870 & $2.696 \mathrm{Km}$ & $\begin{array}{c}\text { Privadas: } \\
\text { - Empresa Ferroviaria Andina }\end{array}$ & $\begin{array}{c}\text { Personas y } \\
\text { mercancías }\end{array}$ & $\begin{array}{c}\text { - Argentina } \\
\text { - Chile }\end{array}$ \\
\hline
\end{tabular}




\begin{tabular}{|c|c|c|c|c|c|}
\hline & & & $\begin{array}{c}\text { S.A. } \\
\text { - Empresa Ferroviaria } \\
\text { Oriente S.A. }\end{array}$ & & - Brasil \\
\hline COLOMBIA & 1850 & $1.991 \mathrm{Km}$ & $\begin{array}{c}\text { Privadas: } \\
\text { - Holdtrade Atlántico } \\
\text { - Ferrocarriles del Norte de } \\
\text { Colombia S.A. } \\
\text { - Promotora Ferrocarril de } \\
\text { Antioquia S.A.S }\end{array}$ & $\begin{array}{l}\text { Personas y } \\
\text { mercancías }\end{array}$ & - Océano Atlántico \\
\hline ECUADOR & 1873 & $965 \mathrm{Km}$ & $\begin{array}{c}\text { Pública: } \\
\text { - Ferrocarriles del Ecuador } \\
\text { EP }\end{array}$ & Personas & 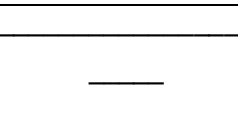 \\
\hline PERÚ & 1851 & $1.906,6 \mathrm{Km}$ & $\begin{array}{c}\text { Privadas: } \\
\text { - Ferrovías Central Andina } \\
\text { S.A. } \\
\text { - Ferrocarril Transandino S.A. } \\
\text { - PeruRail S.A. } \\
\text { - Machu Pichu Train }\end{array}$ & $\begin{array}{l}\text { Personas y } \\
\text { mercancías }\end{array}$ & - Chile \\
\hline
\end{tabular}

Fuentes: Elaboración propia con datos de: Para Bolivia: (Velásquez-Castellanos \& Pacheco Torrico, 2017) (Loclugster, 2018) (Empresa Ferroviaria Andina S.A., 2018) (Empresa Ferroviaria Oriente S.A., 2018). Para Colombia: (Nieto, 2011) (Holdtradeatlantico, 2018) (Fenoco, 2018) (Ferrocarrilantioquia, 2018). Para Ecuador: (Monge \& Yagüe Perales, 2016) (Ferrocarriles del Ecuador, 2018). Para Perú: (Contreras Carranza, 2010) (Prolnversión, 2018)

La importancia de potenciamiento de la red ferroviaria en estos países por parte de China, está determinada por factores de diferente naturaleza que se detallan a continuación:

- El primer importador de productos mineros de Perú es China (Atlas of Economic Complexity, 2017) y, desde el descubrimiento de la presencia de litio en el desierto del Salar de Uyuni, China ha demostrado un fuerte interés en cuanto a la inversión en Bolivia. Actualmente, China está entre los primeros importadores del litio boliviano y ha creado joint ventures entre empresas bolivianas y nacionales para su extracción, en el país suramericano ( Hancock, Ralph, \& Ali, 2017). Por lo tanto, la importancia de la inversión en el sector ferroviario se debe a que tanto en Perú como en Bolivia este sistema de transporte es utilizado también para los derivados de la actividad minera (Wilmsmeier, 2007) y su optimización puede facilitar el comercio de minerales con el socio asiático.

- La red ferroviaria ecuatoriana es utilizada con fines turísticos; sin embargo, para la creación de una línea que conecte con los miembros de la CAN es necesario modernizar la red ecuatoriana. Actualmente, Ecuador mantiene relaciones estratégicas con China en 


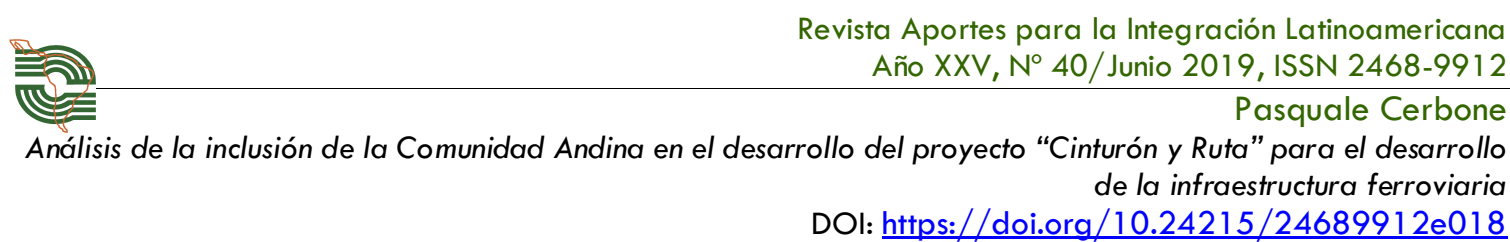

cuanto a la realización de infraestructuras (Evan Ellis, 2018), por lo que el socio asiático podría buscar una oportunidad en la modernización de su infraestructura ferroviaria.

- El ferrocarril en Colombia desemboca en el océano Atlántico. Esta salida podría constituir una forma alternativa al comercio terrestre transoceánico, diferente del que pasa por la carretera Panamericana y de los multimodales que cruzan por el estrecho de Panamá; lo que podría posicionar a Colombia como un nudo logístico estratégico en el cual invertir.

\section{3. Existencia de planes de mejora de la infraestructura ferroviaria entre los países miembros de la CAN}

Debido a las estrategias de incremento de los flujos comerciales, en todos los países miembros de la CAN existen en la actualidad, planes de mejora de la red ferroviaria o de implementación de nuevas líneas; lo que demuestra una atención particular por parte de los gobiernos de estos países en este tema, como factor generador de bienestar y crecimiento económico. De hecho, en Bolivia, un país en donde la red ferroviaria constituye un medio de transporte esencial para la economía nacional, se han formulado planes para la construcción de una línea bioceánica, que conectaría Bolivia con Perú y Paraguay (Ariñez, 2018).

En Ecuador, la Secretaría Nacional de Planificación y Desarrollo ha formulado un proyecto en el 2017 sobre la implementación de trenes eléctricos de carga (SENPLADES, 2017); además, el actual presidente ecuatoriano, Lenín Moreno, ha anunciado la construcción futura de una línea de ferrocarriles para carga y personas en las regiones costeras de Manabí y Guayas (Medina, 2018). Asimismo, en Perú se aprobó en el 2015 el "Plan Nacional de Desarrollo Ferroviario" (Ministerio de Transporte y Comunicaciones , 2015), que ha conllevado la formulación de 13 nuevos proyectos relativos a este sector estratégico (Redacción Gestión, 2016).

En Colombia, en cambio, se registra una disminución de la inversión en este sector y se espera una recuperación de la misma, dada la importancia estratégica de este medio para el comercio nacional e internacional (Redacción Dinero, 2017). De hecho, durante las últimas campañas electorales, para las elecciones presidenciales, diferentes candidatos 


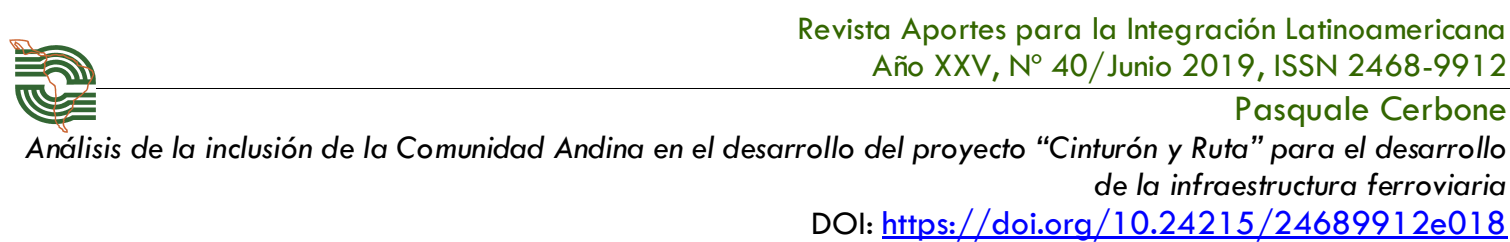

propusieron la recuperación del ferrocarril (Redacción El Colombiano, 2018), sin especificar las fuentes de inversión para la realización de este proyecto. De esto se puede deducir, que en el país se percibe la importancia que tiene esta infraestructura más que no se prioriza su mejora al interno de los planes económicos del Estado. Por eso, de realizarse una propuesta concreta por parte de los países miembros de la CAN, según lo que se propone en este artículo, Colombia podría encontrar en China un aliado fundamental para la mejora de su infraestructura ferroviaria.

\section{4. La política exterior de China y su visión de la cooperación internacional} La política exterior del gigante asiático descansa en la realización de los cincos "Principios de Coexistencia Pacífica" formulados en 1954 y que también en la actualidad, definen los pilares de sus relaciones internacionales: 1) el respeto mutuo por la soberanía y la integridad territorial; 2) la no agresión mutua; 3) la no interferencia en los asuntos internos de otros países; 4) la igualdad y beneficio mutuo; 5) la coexistencia pacífica (Ministry of Foreign Affairs of the People's Republic of China, 2018).

Como consecuencias de su aplicación, el presidente chino Xi Jinping sostuvo, en más de una ocasión, la idea por la cual el proyecto de la nueva ruta de la seda se instaura en una visión de "ganar-ganar" válida para todos los países involucrados (Rocha Pino, 2017). La idea de mutua ganancia, se inserta en el marco conceptual que guía la cooperación "sursur", de la cual China es uno de los mayores promotores desde el fin de la Guerra Fría. Particularmente, con el fin de ese conflicto China pudo empezar a tener más amplias relaciones con América Latina, debido a la posibilidad que la región tuvo de desvincularse progresivamente de la influencia de los Estados Unidos sobre las decisiones en política. Esto favoreció el ingreso de China como socio estratégico de los países considerados en tema de cooperación (Crivelli Minutti \& Lo Brutto, 2018). De hecho, pese al rápido crecimiento económico que ha conocido el gigante asiático, como afirma Brito (2018), China se autopercibe y define como un país del sur del mundo y busca espacio entre los países que pertenecen a la misma categoría, proyectando en ellos la realización de su visión de la política internacional, en la cual no existe una potencia hegemónica, sino el derecho a la tutela de los intereses particulares por parte de los diferentes actores globales. En este sentido, la subregión andina se proyecta como interlocutor de la 


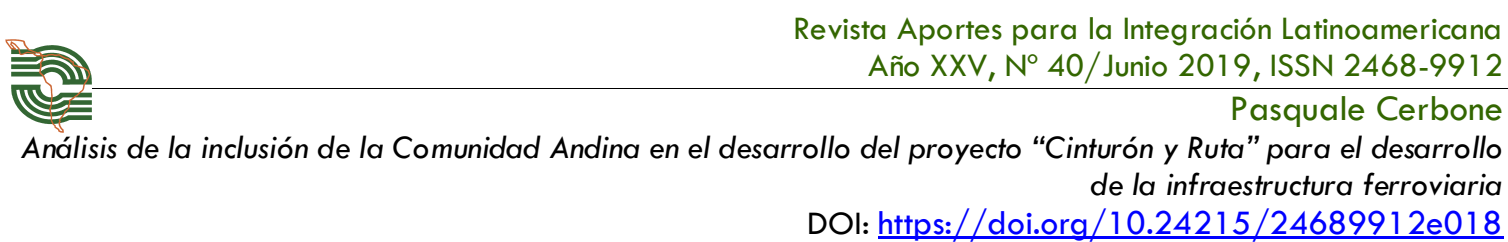

potencia asiática, con la cual diseñar proyectos de mutua ganancia, en el respeto de los mutuos intereses. De hecho, tanto China como los miembros de la CAN han demostrado participar en foros internacionales con el propósito de impulsar el crecimiento de las economías en desarrollo o emergentes (Quirós, 2017), gracias a la mutua colaboración. Para el caso específico, se puede mencionar la existencia del Foro China-CELAC, creado mediante una declaración conjunta de los países que participan en el mismo, en el 2014 en la ciudad de Brasilia (China-CELAC Forum, 2018), entre los cuales se encuentran los países que integran la CAN. Pese a los elementos positivos mencionado, no se pueden omitir las dudas que surgen a propósito de los nuevos planes chinos en cuanto a la realización de un proyecto geopolítico hegemónico a nivel global. De hecho, podría considerarse al plan CYR como un elemento para favorecer a China en la competencia con Estados Unidos, acelerando el ciclo del cual habla Guzmán (2010) que la llevaría a afirmarse a nivel mundial como la nueva mayor potencia económica y política, y por el cual es necesario crear un diferente sistema global de alianzas.

\section{LA POLÍTICA EXTERIOR DE CHINA Y SU VISIÓN DE LA COOPERACIÓN INTERNACIONAL}

Entre los elementos desfavorables sobre el tema analizado, el principal es la inexistencia de una propuesta concreta por parte de los miembros de la CAN sobre el plan CYR. De hecho, no se encuentran planes nacionales de gobiernos o propuestas realizadas por las instituciones de la CAN y ni siquiera producción académica que haga referencia a una eventual proyección de la organización andina en la nueva ruta de la seda. Además, en la literatura revisada y en las informaciones disponibles en el sitio oficial de la organización internacional, no se evidencia la propuesta de una coordinación interna a la CAN en cuanto a proyectos de infraestructura vial relativos a redes ferroviarias. Eso puede depender de las prioridades que han establecido los países miembros en cuanto a la integración de planes para la infraestructura de transporte, mismos que se basan sobre todo en la construcción de carreteras. Por último, como afirma Van Klaveren (2018) uno de los mayores problemas internos a la CAN es la falta de cohesión que se crea cuando se afirman, en los países miembros, gobiernos con ideologías opuestas, lo que dificulta la ampliación del proyecto de integración hacia temas diferentes del comercio interregional. Asimismo, se puede apreciar que existen dificultades externas a la CAN que se podrían asociar a una imposibilidad de aplicación de la propuesta. La principal es, con mucha 


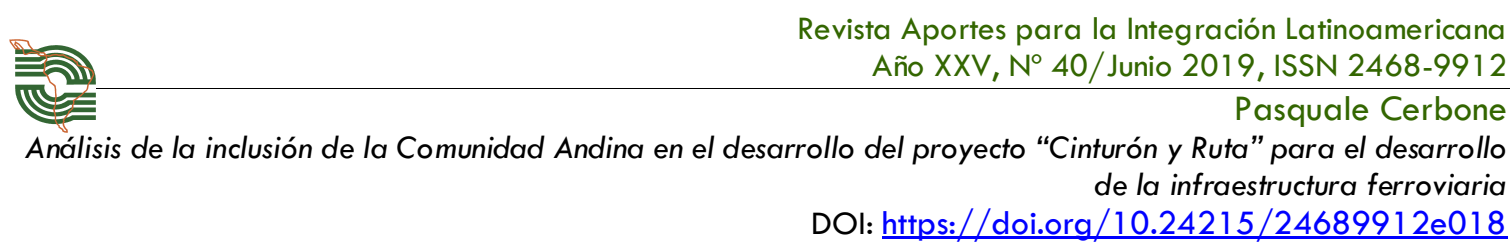

probabilidad, la resistencia demostrada por los Estados Unidos a la expansión del proyecto chino en el continente americano, misma que viene reforzada por la política comercial del actual presidente Donald Trump, orientada principalmente hacia la toma de acuerdos bilaterales y la ruptura de los esquemas comerciales tradicionales (Grabendorff, 2018). Otro elemento a considerarse está constituido por el escaso control en las zonas de frontera entre los países de América del sur, que pese a la necesidad de integración es necesario debido a la inseguridad que generan el narcotráfico y la criminalidad a ello conectada (Emmerich, 2015). Este problema es aún más importante, si consideramos que según el Departamento de Estado de los Estados Unidos, lo cuatro países integrantes de la CAN se posicionan entre los 22 países que mayormente están involucrados en el narcotráfico global (Bureau for International Narcotics and Law, 2018) lo que podría frenar la idea de impulsar la integración en cuanto a vías de comunicación entre los países considerados, por el riesgo de que aumenten el narcotráfico y el contrabando. En fin, hay que considerar que la región latinoamericana es la que presenta la mayor tasa de corrupción a nivel mundial, así como es confirmado a través de los datos brindados por Transparency International (2018), lo que crea desconfianza recíproca entre los gobiernos de la región andina, marcando la inexistencia de una visión regionalista compartida entre los diferentes países que la componen (Candia Baeza, 2007).

Al haber determinado los factores que influirían positivamente y negativamente en la propuesta planteada, se realiza a continuación una evaluación global de la propuesta.

\section{MÉTOdo Y TÉCNICA DE INVESTIGACIÓN}

Para evaluar la propuesta considerada se ha elegido como parte de la metodología la técnica del análisis de las fortalezas, oportunidades, debilidades y amenazas (FODA) con asignación de valores ponderados. Por eso, relacionando elementos internos y externos relativos a la propuesta presentada, se puede determinar el nivel de factibilidad de la misma. A este propósito, se hizo referencia a la teoría de Armas Rodríguez (2018), quien propone asociar la teoría de juegos a la herramienta que se va a utilizar. De hecho, al ser cada fenómeno determinado por el comportamiento adoptado por los actores que participan en el mismo, es necesario tomar en consideración dicho comportamiento en la determinación del FODA. Entonces, se propone un análisis en el cual se tienen en 


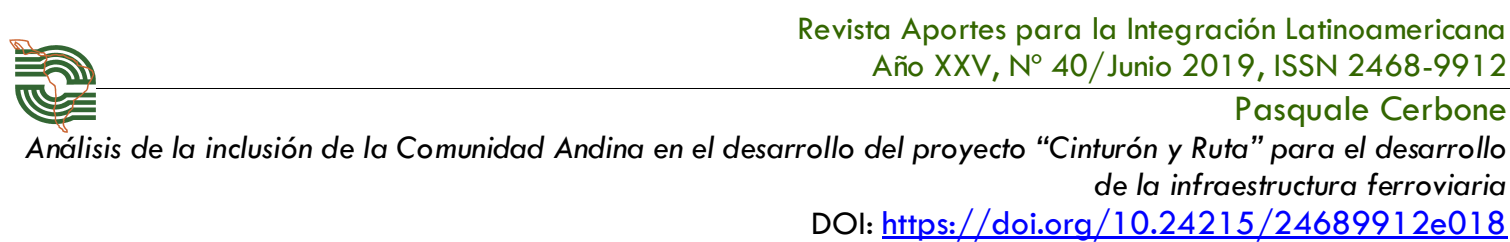

consideración "fortalezas, oportunidades, debilidades y amenazas" relacionadas con los países miembros de la CAN y China. En cuanto a los elementos del FODA, se procedió a buscarlos a través de una amplia revisión bibliográfica, que se realizó de forma previa a la redacción del artículo. Sin embargo, debido a que uno de los límites de esta técnica es la posibilidad de calificar subjetivamente los diferentes elementos, se ha procedido a atenuar esta falla de la siguiente forma: i) la relevancia de cada elemento, para los fines de este estudio, fue acordada mediante un panel de docentes expertos en las áreas de geopolítica, integración y comercio internacional; ii) se ha utilizado una "matriz de balance de fuerza" con el fin de establecer una ponderación de la relación que existe entre factores internos y externos, asignando un valor numérico; iii) cada uno de los integrantes del panel ha redactado la matriz de forma independiente, basando sus calificaciones en una visión basada en el respectivo ámbito de experticia. En cuanto a la fase de ponderación de los valores a asignarse, como sugiere Pardo Fernández (2005), se procedió respondiendo a dos preguntas consecuentes para cada una de las relaciones a analizarse, de la forma en que se indica a continuación:

- Para la relación "F/O" las preguntas fueron: i) ¿Puede esta fortaleza permitir disfrutar de esta oportunidad? ii) ¿Con qué probabilidad?

- Para la relación "F/A": i) ¿Puede esta amenaza neutralizar a esta fortaleza? ii) ¿Con qué probabilidad?

- Para la relación "D/O”: i) ¿Puede esta debilidad perjudicar el aprovechamiento de esta oportunidad? ii) ¿Con qué probabilidad?

- Para la relación "D/A": i) ¿Puede esta debilidad incrementar las posibilidades de realización de esta amenaza? ii) ¿Con qué probabilidad?

A cada una de las primeras preguntas se respondió con un "si" o "no". La respuesta "no" correspondió a la asignación de un valor igual a 0 a la relación analizada. La respuesta "si", dio acceso a la segunda pregunta, a la cual se respondió asignando un valor entre 1 y 3 , dependiendo de la probabilidad con la cual se podría verificar la situación indicada en la pregunta: 1 = poco probable; 2 = probable; $3=$ muy probable. Así, se produjo un esquema compuesto por 4 zonas: i) la "zona de poder", determinada por la relación entre fortalezas y oportunidades; ii) la "zona de protección" basada en la relación entre fortalezas y 


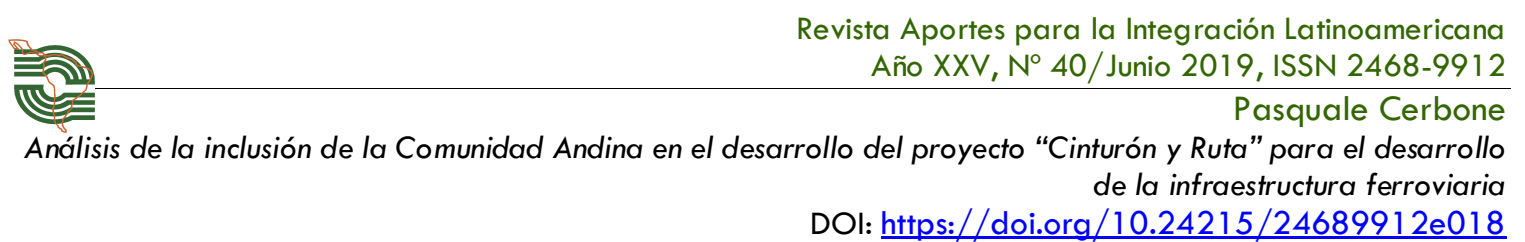

amenazas; iii) la "zona de freno" conformada por la relación entre debilidades y oportunidades; iv) la "zona crítica" en donde se relacionan debilidades y amenazas. La nomenclatura utilizada fue formulada por Pardo Fernández (2005).

Para los fines de la ponderación, cada zona expresa como resultado la media de las medias de los valores de las diferentes relaciones analizadas. La media de hecho, es una medida de tendencia central que puede expresar la relación entre los elementos analizados de forma estandarizada. Por lo tanto, el máximo potencial de una zona será expresado por un valor igual a 3 , mientras que el mínimo será expresado por un valor igual a 0.

\section{Resultados}

La revisión bibliográfica permitió identificar factores internos y externos capaces de favorecer u obstaculizar la realización de la propuesta analizada.

A continuación se enumeran dichos factores:

- Fortalezas: $\mathbf{F}_{1}$ ) La integración comercial entre los países miembros de la CAN y de los mismos con China. $\mathbf{F}_{2}$ ) La existencia de una infraestructura ferroviaria previa en todos los países miembros de la CAN. $\mathbf{F}_{3}$ ) La existencia de planes de mejora de la infraestructura ferroviaria por parte de los países miembros de la CAN. $\mathbf{F}_{4}$ ) La existencia de una cultura de cooperación "sur-sur" en China y su aplicación en los países miembros de la CAN.

- Debilidades: $\mathbf{D}_{1}$ ) La falta de proyección geopolítica de la CAN en el proyecto de la nueva ruta de la seda. $\mathbf{D}_{2}$ ) La falta de coordinación interna en la CAN en cuanto a planes de desarrollo de una red ferroviaria que interconecte sus integrantes. $\mathbf{D}_{3}$ ) La prioridad dada al transporte por carreteras, por parte de los países miembros de la CAN. $\mathbf{D}_{4}$ ) La falta de cohesión política entre los países miembros de la CAN.

- Oportunidades: $\mathbf{O}_{1}$ ) La participación en una red comercial más amplia, mediante la participación en el proyecto CYR. $\mathbf{O}_{2}$ ) La existencia de apoyo por parte de organizaciones internacionales sobre la mejora de la infraestructura ferroviaria. $\mathrm{O}_{3}$ ) El crecimiento económico conjunto entre los miembros de la CAN. $\mathbf{O}_{4}$ ) $\mathrm{El}$ crecimiento de las comunicaciones entre los países miembros de la CAN. 
- Amenazas: $A_{1}$ ) La resistencia de los Estados Unidos a la expansión del proyecto chino en América. $A_{2}$ ) La existencia de problemas de seguridad y control en las fronteras a nivel regional: con eso se hace referencia a los problemas de contrabando y narcotráfico. $A_{3}$ ) Alto índice de corrupción de los países de la región latinoamericana. $\mathbf{A}_{4}$ ) Las diferencias de visión regionalista entre los gobiernos de América Latina.

La tabla a continuación expresa los valores asignados a la relación entre los factores internos y externos del sistema considerado.

Tabla 5. Valores del FODA ponderado, según la visión de un experto en comercio exterior.

\begin{tabular}{|c|c|c|c|c|c|c|c|c|c|c|}
\hline & 01 & 02 & O3 & 04 & $\begin{array}{c}\text { Medias de las } \\
\text { relaciones } \\
\text { F/O-D/O }\end{array}$ & A1 & A2 & A3 & A4 & $\begin{array}{c}\text { Medias de las } \\
\text { relaciones } \\
\text { F/A - D/A }\end{array}$ \\
\hline F1 & 3 & 2 & 3 & 2 & 2.5 & 2 & 1 & 1 & 3 & 1.75 \\
\hline F2 & 2 & 2 & 2 & 2 & 2 & 1 & 2 & 2 & 2 & 1.75 \\
\hline F3 & 2 & 2 & 3 & 2 & 2.25 & 2 & 2 & 3 & 3 & 2.5 \\
\hline F4 & 2 & 2 & 2 & 2 & 2 & 2 & 2 & 1 & 2 & 1.75 \\
\hline $\begin{array}{l}\text { Medias } \\
\text { totales }\end{array}$ & & & & & 2.18 & & & & & 1.93 \\
\hline D1 & 3 & 2 & 2 & 1 & 2 & 2 & 1 & 1 & 2 & 1.5 \\
\hline D2 & 2 & 1 & 1 & 2 & 1.5 & 1 & 2 & 2 & 2 & 1.75 \\
\hline D3 & 3 & 2 & 1 & 1 & 1.75 & 1 & 3 & 3 & 1 & 2 \\
\hline D4 & 2 & 2 & 2 & 3 & 2.25 & 3 & 3 & 3 & 3 & 3 \\
\hline Medias & & & & & 1.87 & & & & & 2.06 \\
\hline
\end{tabular}

Fuente: Elaborado por el autor. 
Análisis de la inclusión de la Comunidad Andina en el desarrollo del proyecto "Cinturón y Ruta" para el desarrollo de la infraestructura ferroviaria DOI: https://doi.org/10.24215/24689912e018

Tabla 6. Valores del FODA ponderado, según la visión de un experto en integración

\begin{tabular}{|c|c|c|c|c|c|c|c|c|c|c|}
\hline & 01 & 02 & 03 & 04 & $\begin{array}{c}\text { Medias de las } \\
\text { relaciones } \\
\text { F/O-D/O }\end{array}$ & A1 & A2 & A3 & A4 & $\begin{array}{c}\text { Medias de las } \\
\text { relaciones } \\
\text { F/A - D/A }\end{array}$ \\
\hline F1 & 3 & 2 & 3 & 3 & 2.75 & 3 & 1 & 2 & 2 & 2 \\
\hline F2 & 2 & 3 & 3 & 3 & 2.75 & 3 & 3 & 2 & 3 & 2.75 \\
\hline F3 & 2 & 3 & 3 & 3 & 2.75 & 3 & 2 & 2 & 1 & 2 \\
\hline F4 & 2 & 2 & 3 & 3 & 2.5 & 3 & 3 & 3 & 1 & 2.5 \\
\hline $\begin{array}{l}\text { Medias } \\
\text { totales }\end{array}$ & & & & & 2.68 & & & & & 2.31 \\
\hline D1 & 3 & 2 & 2 & 2 & 2.25 & 3 & 2 & 1 & 3 & 2.25 \\
\hline D2 & 3 & 3 & 3 & 3 & 3 & 1 & 2 & 0 & 1 & 1 \\
\hline D3 & 3 & 3 & 3 & 2 & 2.75 & 0 & 1 & 0 & 0 & 0.25 \\
\hline D4 & 3 & 3 & 3 & 3 & 3 & 3 & 3 & 2 & 3 & 2.75 \\
\hline Medias & & & & & 2.75 & & & & & 1.56 \\
\hline
\end{tabular}

totales

Fuente: Elaborado por el autor.

Tabla 7. Valores del FODA ponderado, según la visión de un experto en geopolítica.

\begin{tabular}{|c|c|c|c|c|c|c|c|c|c|c|}
\hline & 01 & 02 & 03 & 04 & $\begin{array}{c}\text { Medias de las } \\
\text { relaciones } \\
\text { F/O-D/O }\end{array}$ & A1 & A2 & A3 & A4 & $\begin{array}{c}\text { Medias de las } \\
\text { relaciones } \\
\text { F/A - D/A }\end{array}$ \\
\hline F1 & 3 & 0 & 3 & 2 & 2 & 2 & 3 & 3 & 0 & 2 \\
\hline F2 & 3 & 3 & 1 & 3 & 2.5 & 0 & 3 & 2 & 0 & 1.25 \\
\hline F3 & 3 & 3 & 3 & 3 & 3 & 0 & 3 & 3 & 0 & 1.5 \\
\hline F4 & 3 & 1 & 3 & 1 & 2 & 1 & 0 & 3 & 3 & 1.75 \\
\hline $\begin{array}{l}\text { Medias } \\
\text { totales }\end{array}$ & & & & & 2.38 & & & & & 1.63 \\
\hline D1 & 3 & 0 & 1 & 1 & 1.25 & 3 & 0 & 0 & 2 & 1.25 \\
\hline D2 & 3 & 1 & 3 & 2 & 2.25 & 1 & 1 & 0 & 0 & 0.5 \\
\hline D3 & 0 & 3 & 1 & 2 & 1.5 & 0 & 0 & 0 & 0 & 0 \\
\hline D4 & 3 & 3 & 3 & 3 & 3 & 3 & 3 & 3 & 3 & 3 \\
\hline
\end{tabular}

totales

Fuente: Elaborado por el autor.

\section{CONCLUSIONES}

La matriz FODA realizada bajo tres diferentes perspectivas ha generado resultados muy diferentes. Eso permite llegar conclusiones más completas.

En primer lugar, desde el punto de vista del comercio internacional las cuatro zonas identificadas por la matriz no presentan diferencias sustanciales. De hecho, pese a que la zona de poder es la que presenta el valor más alto, la zona crítica sigue con una 


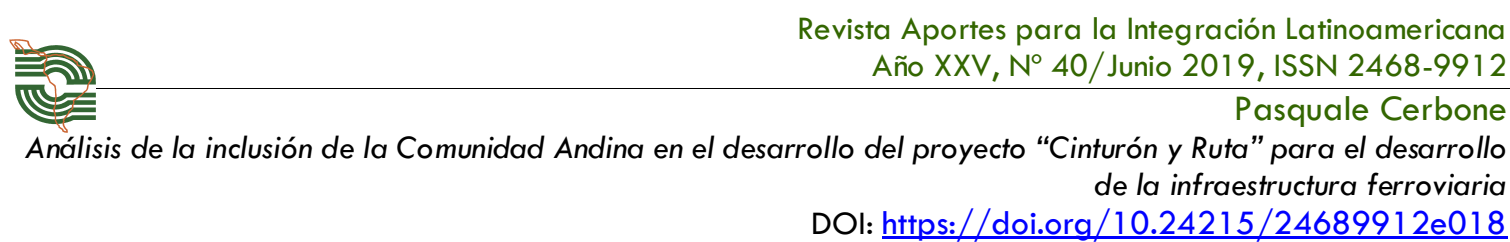

diferencia mínima, lo que puede dejar pensar que el plan de la inclusión de los países miembros de la CAN en el proyecto CYR, no puede alterar significativamente la situación ya existente en cuanto al comercio exterior: al ser los países miembros de la CAN productores de bienes muy similares, el comercio interno al espacio ocupado por la organización en cuestión no puede incrementarse más allá de los límites actuales. Lo mismo vale para el comercio con China en cuanto, si bien la infraestructura ferroviaria agilitaría el transporte de los productos chinos internamente, no ayudaría sino mínimamente el incremento de las exportaciones.

Desde el punto de vista de la integración regional, el cuadro es peor: bajo esta perspectiva, la zona de freno es la que presenta el valor más alto, seguido por la zona de poder, que se diferencia de este por muy poco. Eso indica que las debilidades de los actores de la CAN, son más influyentes que sus fortalezas, tanto de no permitir aprovechar las oportunidades que la inclusión al plan de las "nuevas rutas de la seda", brinda. Por esta razón, antes de incluirse en dicho proyecto sería necesario que la CAN trabaje en eliminar las debilidades que lo obstaculizan, entre las cuales un papel relevante es jugado por la falta de cohesión entre sus miembros. En cuanto al análisis según la perspectiva geopolítica, se produce un resultado positivo en la "zona de poder" igual a 2.38 puntos, expresando este la media mayor frente a las otras zonas de la matriz, alcanzando casi el máximo resultado previsto. Además, es seguramente positivo el asunto por el cual la cuarta zona, la "zona crítica", presenta el resultado inferior, destacándose de la zona de poder con un valor suficientemente alto. Esto da fuerza a la propuesta, en términos geopolíticos, al significar que la relación entre debilidades y amenazas no es tan fuerte de poder impulsar las segundas y que por ende las fortalezas y oportunidades del sistema analizado superan el potencial expresado por los elementos negativos influyentes en el mismo. De hecho, desde el punto de vista geopolítico, la participación de los países miembros de la CAN al proyecto CYR puede permitir ampliar su espacio de influencia tanto a nivel regional como global. Según la propuesta realizada en este artículo, la edificación de una infraestructura ferroviaria entre los países considerados representaría, históricamente, la tercera obra de infraestructura de comunicación vial más importante del continente, después de la construcción del canal de Panamá y de la carretera Panamericana. Esto, desde una visión de la geopolítica crítica, podría cambiar la 


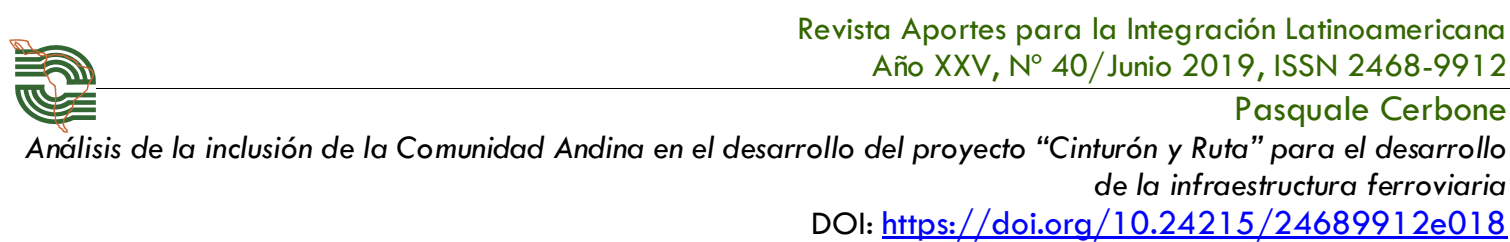

representación que los países integrantes de la CAN tienen de ellos mismos, en cuanto Estados y en cuanto organización subregional y del peso político que son capaces de ejercer sobre el resto de la región latinoamericana, lo que representaría un contrapeso, frente a la ganancia que tendría China en incursionar mayormente en la región, como consecuencia de la realización del proyecto infraestructural del cual se ha discutido.

En definitiva, en cuanto a la realización de la propuesta puede decirse que el FODA muestra que la actual situación de los países miembros de la CAN no permitiría explotar todo el potencial de una infraestructura del tipo que se ha descrito, en cuanto los Estados de la organización andina deberían priorizar la solución de dificultades internas para poder surgir a nivel regional y global. De hecho, considerando la magnitud de la inversión que se debería concretar para la realización de la infraestructura, el hecho que la misma no produzca beneficios comerciales para los países miembros de la CAN resulta un factor desalentador. Se deduce que el análisis de la propuesta de inclusión de los países de la CAN en el proyecto CYR tiene un éxito prevalentemente negativo, pese al interés mostrado por China en la realización de este proyecto también en la región suramericana y al potencial geopolítico que tiene el mismo para los países andinos considerados.

Se recomienda seguir en la investigación de este tema, profundizando en aspectos que, debido a las propias limitaciones de espacio y tiempo, no se analizaron al interno de este artículo, entre los cuales los efectos que la adopción de la infraestructura puede conllevar en término de modificación del intercambio desigual, que caracteriza la relación comercial de los miembros de la CAN y China, y la relación centro-periferia, que constituye un tema aún actual para el desarrollo de los países suramericanos considerados.

\section{BiBLIOGRAFÍA}

Agencia de Promoción de la Inversión Privada-Perú. Prolnversión. (2018). Inversión Extranjera. Recuperado de https://www.proinversion.gob.pe/modulos/jer/PlantillaPopUp.aspx?ARE=0\&PFL=0\&JER=5 $\underline{975}$

Agencia de Promoción de la Inversión Privada-Perú. Prolnversión. (2018). Cartera de Proyectos. https://www.proyectosapp.pe/modulos/JER/PlantillaProyectosResumenes.aspx?are=0\&prf $=2 \& j e r=5681 \& \mathrm{sec}=24$ 


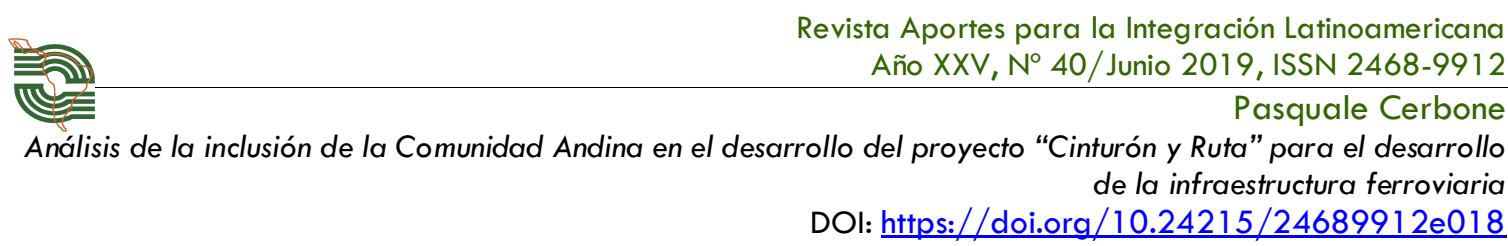

Agencia Nacional de Infraestructura. (2018). Recuperado de https://www.ani.gov.co/

Amighini, A. (2017). Towards a New Geography of Trade? En A. Amighini. (Ed.), China's Belt and Road: a Game Changer? (pp. 121-140). Milano, Italia: ISPI. DOI 10.19201/ispichinasbelt

Ariñez, R. (2 de Octubre de 2018). Tras el fallo, Bolivia decide acelerar el tren bioceánico y mira a puerto Busch para llegar al mar. La Razón Digital. Recuperado de https://consuladogeneraldebolivia.com.ar/tras-elfalloboliviadecideacelerareltrenbioceanicoy-mira-a-puerto-busch-para-llegar-al-marl

Asociación Latinoamericana de Integración. (2008). Integracion física y digital. Integración física y distribución. Recuperado de http://www.aladi.org/nsfaladi/integracion.nsf/f2111b36d7a2adad03256e60004a746a/f00ee 323c676126c032574e3004d9c8c?OpenDocument

ATLAS of Economic Complexity (2017). Where did Bolivia export to in 2016? Recuperado de:

http://atlas.cid. harvard.edu/explore/?country=31\&partner=undefined\&product=undefined\&p $\underline{\text { roductClass }=H S \& \text { startYear }=\text { undefined } \& \text { target }=\text { Partner } \& \text { year }=2016}$

Banco Central del Ecuador. (Sin fecha). Inversion extranjera directa. Recuperado de https://www.bce.fin.ec/index.php/component/k2/item/298-inversi\%C3\%B3n-extranjeradirecta

Banco de la República Colombia (Sin fecha). Flujos de inversión directa. Balanza de pagos. Recuperado de http://www.banrep.gov.co/es/inversion-directa

Banco Interamericano de Desarrollo (2017). Evaluación de las Asociaciones PúblicoPrivadas en Infraestructura.Nueva York: BID. Recuperado de http://www.iadb.org/ove/PPP

Beria, P., Grimaldi, R., Albalate, D., \& Bel, G. (2018). Delusion of success: Cost and demand of high-speed rail in Italy and Spain. Transport Policy, (68), 63-79. Recuperado de https://re.public.polimi.it/retrieve/handle/11311/1015984/186783/Beria\%20Bel\%20et\%20al \%20\%20Mismatches $\% 20 H S R \% 20$ Italy $\% 20$ n 20 Spain $\% 20 \% 20 P A P E R \% 2013 \% 20 \% 5 B S$ ENT\%5D.pdf

Bonilla, O. (2012). The Manta-Manaus project: nature, capital and plunder. En H. Healy , J. Martínez-Alier, L. Temper, M. Walter, \& J.-F. Gerber, Ecological Economics from the Ground Up (pp. 89-109). Londres, UK: Routledge.

Brito, G. (2018). La política exterior China y su proyección hacia América Latina y el Caribe en el siglo XXI. Imaginarios y representaciones geopolíticas. Geopolítica(s) Revista de estudios sobre espacio y poder, 9(1), 63-85. https://doi.org/10.5209/GEOP.55556 


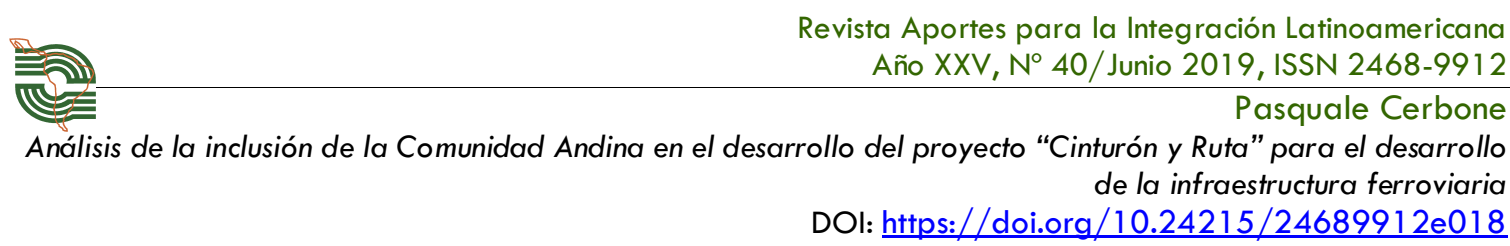

Bureau for International Narcotics and Law. (2018). International Narcotics Control Strategy Report. Washington D.C.: United States Department of States. Recuperado de https://www.state.gov/2019-international-narcotics-control-strategy-report/

Corporación Andina de Fomento (CAF). (2017). América Latina debe invertir al menos 5\% en infraestructura al año para dar el salto en competitividad. Recuperado de https://www.caf.com/es/actualidad/noticias/2017/05/america-latina-debe-invertir-al-menos5-en-infraestructura-al-ano-para-dar-el-salto-en-competitividad/

Corporación Andina de Fomento (CAF). (2005). Se suscribió un convenio por US\$125.8 millones para transporte $y$ competitividad en Ecuador. Recuperado de https://www.caf.com/es/actualidad/noticias/2005/08/se-suscribio-un-convenio-por-us-1258millones-para-transporte-y-competitividad-en-ecuador/

Candia Baeza, C. (2007). Filosofía, identidad y pensamiento político en Latinoamérica. Polis, Revista Latinoamericana, (18), 1-16. Recuperado de https://journals.openedition.org/polis/4054

Castillo-Manzano, J. I., Castro-Nuño, M., López-Valpuesta, L., Pedregal-Tercero, D. J., \& Garrido-Michó, J. M. (2018). High Speed Rail: Fast tracking tourism in the EU? Annals of Tourism Research, 71, DOI: https://doi.org/10.1016/j.annals.2018.02.005

Chan, G. (2017). From laggard to superpower: Explaining China's High-Speed Rail 'Miracle', Kokusai Monday (International Affairs), (661), 1-9. Recuperado de https://www2.jiia.or.jp/search.php?hl=ja\&as sitesearch=\%2F\%2Fwww2.jiia.or.jp\%2F\&q=C $\underline{\text { han } \% 2 C+G}$

China-CELAC Forum. (s/d). Foro China-CELAC. Recuperado de http://www.chinacelacforum.org/esp/

China-CELAC Forum. (s/d). Foro de Cooperación en Infraestructura China-América Latina y el Caribe. Recuperado de http://www.chinacelacforum.org/esp/zyiz 2/zylyflt/zlijcsslt/

Comisión Económica para América Latina (CEPAL). (2014). La inversión en infraestructura en América Latina $y$ el Caribe. Recuperado de: https://www.cepal.org/es/infografias/la-inversion-en-infraestructura-en-america-latina-y-elcaribe

Comisión Económica para América Latina (CEPAL). (2017). La Agenda 2030 y los Objetivos de Desarrollo Sostenible: Una oportunidad para América Latina y el Caribe. Objetivos, metas e indicadores mundiales. Santiago de Chile: CEPAL. Recuperado https://www.cepal.org/es/publicaciones/40155-la-agenda-2030-objetivos-desarrollosostenible-oportunidad-america-latina-caribe 


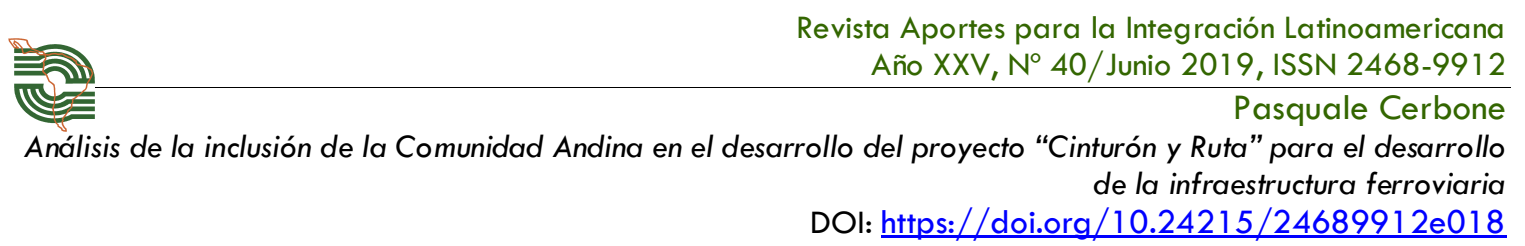

Comunidad Andina. (s/d). Somos Comunidad Andina. Recuperado de http://www.comunidadandina.org/Seccion.aspx?id=189\&tipo=QU\&title=somos-comunidadandina

Comunidad Andina. (s/d). Sistema Andino de Integracion. Recuperado de http://www.comunidadandina.org/Seccion. aspx?id=4\&tipo=SA\&title=sistema-andino-deintegracion-sai

Consejo Suramericano de Infraestructura y Planeamiento, UNASUR. (2017). Insumos para elaborar una estrategia que facilite la Integración Ferroviaria de Suramérica, Argentina: IIRSA-COSIPLAN. Recuperado de http://www.iirsa.org/Document/Detail? Id=4622\#

Contreras Carranza, C. (2010). La economía del transporte en el Perú, 1800-1914. Apuntes Revista de Ciencias Sociales, (66), 59-81. https://doi.org/10.21678/apuntes.66.597

Corporación Peruana de Aeropuertos y Aviación Comercial. (s/d). Página de inicio. Recuperado de http://www.corpac.gob.pe/Main.asp?T=4204

Crivelli Minutti, E., \& Lo Brutto, G. (2018). La cooperación de China en América Latina: ¿hacia una Nueva Economía Estructural? Revista Carta Internacional, 13(2), 123-146. https://doi.org/10.21530/ci.v13n2.2018.806

Dai, X., Xu, M., \& Wang, N. (2018). The industrial impact of the Beijing-Shanghai highspeed rail. Travel Behaviour and Society, (12), 23-29. http://dx.doi.org/10.1016/j.tbs.2018.03.002

De Armas Rodríguez, H. (2018). Método para la elaboración de estrategias dominantes SWOT con el empleo del equilibrio de Nash en juegos matriciales de suma cero. Revista Investigación Operacional, 39(1), 67-86. Recuperado de https://rev-inv-ope.univparis1.fr/volumes-since-2000/volume-39-2018/

De Rus, G. \& Nombela, G. (2007). Is Investment in High Speed Rail Socially Profitable? Journal of Transport Economics and Policy, 41(1), 3-23. Recuperado de https://www.ingentaconnect.com/contentone/lse/jtep/2007/00000041/00000001/art00002

Detsch, C. (2018). Escaramuzas geoestratégicas en el «patio trasero»: China y Rusia en América Latina. Nueva Sociedad, (275), 79-91. Recuperado de https://nuso.org/edicionimpresal

Diaio, M. (2018). Does growth follow the rail? The potential impact of high-speed rail on the economic geography of China. Transportation Research Part A: Policy and Practice, 113, 279-290. DOI: https://doi.org/10.1016/j.tra.2018.04.024 


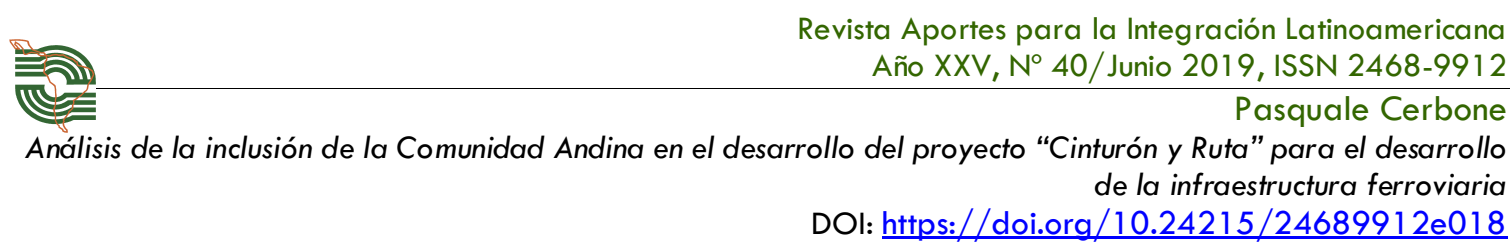

Duque, I., Petro, G. et al. (25 de Mayo de 2018). Candidatos se comprometen a recuperar el ferrocarril. El Colombiano. Recuperado https://www.elcolombiano.com/elecciones-2018colombia/candidatos-se-comprometen-a-recuperar-el-ferrocarril-EC8756710

Durán, S. (2013). Brasil, Ecuador y la Manta-Manaos: escenarios a considerar para una auténtica integración. Quito, Ecuador: Universidad Andina Simón Bolívar Ecuador. Recuperado de https://www.uasb.edu.ec/web/area-de-estudios-sociales-yglobales/publicacion?ecuador-y-la-manta-manaos-escenarios-a-considerar-para-unaautentica-integracion-615

Emmerich, N. (2015). Geopolítica del narcotráfico en América Latina. México: IAPEM. Recuperado https://www.academia.edu/11944162/Geopol\%C3\%ADtica_del narcotr\%C3\%A1fico en Am\%C3\%A9rica Latina

Empresa Ferroviaria Andina S.A. (s/d). Presentación Institucional. Recuperado de http://ferroviaria-andina.com.bo/perfil-corporativo/

Empresa Ferroviaria Oriente S.A. (s/d). Acerca de Nosotros. Recuperado de http://www.fo.com.bo/AcercaDeNosotros/LaEmpresa/default.aspx

Empresa Nacional de Puertos S.A. (s/d). Reseña Histórica. Recuperado de http://www.enapu.com.pe/web/contenido.php?id=1303316655

Evan Ellis, R. (2018). Hacia una asociación estratégica: Las inversiones de China en América Latina. Working Paper Series (WPS)-REDCAEM, (3) Recuperado de: http://chinayamericalatina.com/wp-content/uploads/2018/03/WP-N\%C2\%B03-marzo-2018REDCAEM.pdf

Ferrocarril de Antioquia. (2018). Nosotros. Recuperado de http://www.ferrocarrilantioquia.com/ferrocarril-de-antioquia\#cat33

Ferrocarriles del Ecuador EP. (2018). Recuperado de http://www.ferrocarrilesdelecuador.gob.ec/resena-historica-del-ferrocarril-ecuatoriano/

Ferrocarriles del Norte de Colombia S.A. (2018). Historia del Fenoco. Recuperado de http://www.fenoco.com.co/index.php/quienes-somos/historia-de-fenoco

Fondo Monetario Internacional. (2017). Historia de dos ajustes, Perspectivas económicas: Las Américas, (17). Recuperado de: https://www.imf.org/es/Publications/REO/WH/Issues/2017/05/10/wreo0517

Fondo Monetario Internacional. (2018). Una recuperación despareja. Perspectivas económicas: Las Américas, (18). Recuperado de https://www.imf.org/es/Publications/REONWH/lssues/2018/05/09/wreo0518 


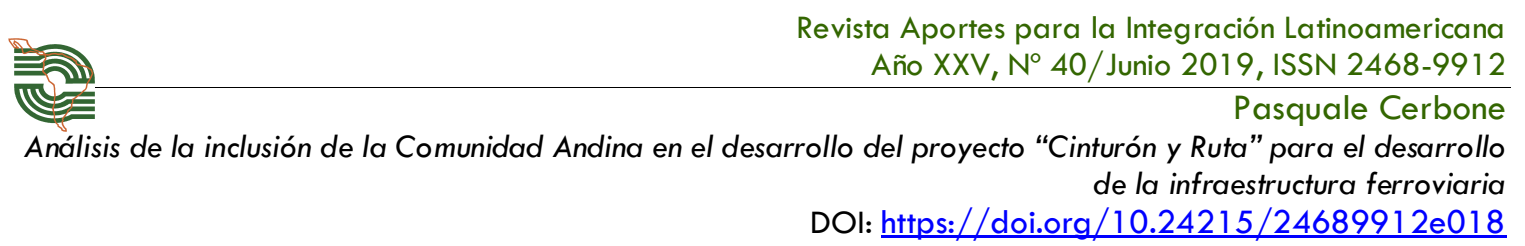

Grabendorff, W. (2018). América Latina en la era Trump. Nueva Sociedad, (275), 47-61. Recuperado de https://nuso.org/articulo/america-latina-en-la-era-trump/

Graziani Mora, J. (2017). Tren bioceánico central: un escenario geopolítico en la configuración de corredores estratégicos suramericanos. Documentos de Opinión Instituto Español de Estudios Estratégicos, (12), 1-17. Recuperado de http://www.ieee.es/contenido/noticias/2017/02/DIEEEO12-2017.html

Guzmán, C. (2010). El ascenso de China y las teorías verticales de relaciones internacionales: Contrastando las lecciones de las teorías de la transición de poder y del ciclo de poder. Revista Uruguaya de Ciencia Política, 19(1), 185-206. Recuperado de http://www.redalyc.org/articulo.oa?id=297322675008

Hancock, L., Ralph, N., \& Ali, S. (2017). Bolivia's lithium frontier: Can public private partnerships deliver a minerals boom for sustainable development? Journal of Cleaner Production, (178), 551-560. https://doi.org/10.1016/j.jclepro.2017.12.264

Holdtrade Atlantico. (2018). Proyecto. Recuperado de http://holdtradeatlantico.com/proyecto/?lang=es

Hong Kong Trade Development Council (2019). The Belt and Road Initiative: Country Profiles. Recuperado de http://chinatraderesearch.hktdc.com/businessnews/article/TheBelt-and-RoadInitiative/TheBelt-and-Road-Initiative-CountryProfiles/obor/en/1/1X000000/1X0A36I0.htm

Indeo, F. (2017). A comprehensive strategy to strengthen China's relations with central asia. En A. Amighini. (Ed), China's belt and road: A game changer? (pp. 35-52). Milán, Italia: ISPI. Recuperado de https://www.ispionline.it/sites/default/files/pubblicazioni/china belt road game changer.pd f

Logistics Capacity Assessments (LCAs). (2018). Bolivia, evaluación de ferrocarriles. Recuperado https://dlca.logcluster.org/pages/releaseview.action;jsessionid=95A6F9EF10A0D1FEE213 D585FF102F02?pageld $=7307712$

Malamud, C. (2015). Integración y cooperación regional en América Latina: diagnóstico y propuestas. Documento de Trabajo Real Instituto Elcano, (15). Recuperado de: http://www.realinstitutoelcano.org/wps/portal/rielcano es/contenido?WCM GLOBAL_CON TEXT=/elcano/elcano es/zonas es/dt15-2015-malamud-integracion-cooperacionregional-america-latina-diagnostico-propuestas

Medina, A. (10 de Octubre de 2018). Cerca de USD 1.000 millones costará el Tren Playero. El Comercio. Recuperado de https://www.elcomercio.com/actualidad/tren- 


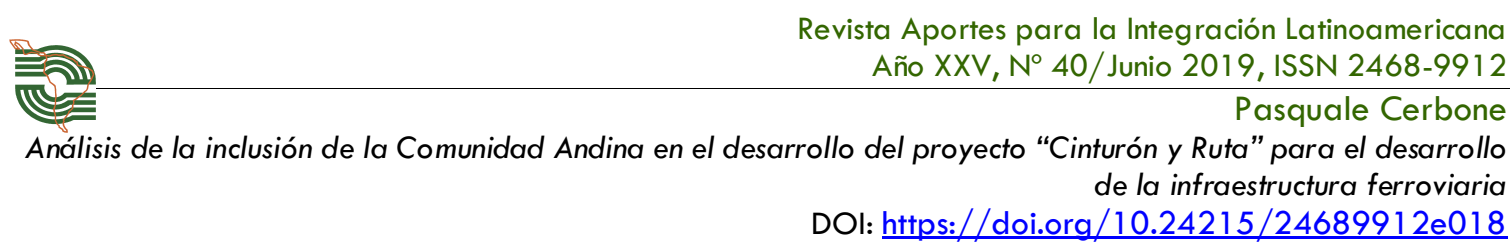

playero-turismo-carga-ecuador.html

Ministerio de Relaciones Exteriores de la República Popular de China. (24 de Noviembre de 2016). Documento sobre la Política de China Hacia América Latina y el Caribe. Recuperado de https://www.fmprc.gov.cn/esp/wjdt/wjzc/t1418256.shtml

Ministerio de Relaciones Exteriores del Estado Peruano. (17 de Mayo de 2019). El Perú participa en foro sobre cooperación internacional para la reducción de la pobreza en China. Recuperado de: https://www.gob.pe/institucion/rree/noticias/28509-el-peruparticipa-en-foro-sobre-cooperacion-internacional-para-la-reduccion-de-la-pobreza-enchina

Ministerio de Relaciones Exteriores del Estado Plurinacional de Bolivia. (19 de Junio de 2018). Evo Morales y Xi Jinping firman 8 Convenios y Memorándums de Entendimiento en beneficio del país. Recuperado de: http://www.cancilleria.gob.bo/webmre/noticia/2565

Ministerio de Relaciones Exteriores y Movilidad Humana de Ecuador. (14 de Diciembre de 2018). Ecuador se adhiere a la iniciativa china de la Franja y la Ruta como resultado de la visión "pragmática" del gobierno. Recuperado de https://www.cancilleria.gob.ec/ecuadorse-adhiere-a-la-iniciativa-china-de-la-franja-y-la-ruta-como-resultado-de-la-visionpragmatica-del-gobierno

Ministerio de Transporte y Comunicaciones de la República del Perú. (2015). Plan Nacional de Desarrollo Ferroviario (Resolución ministerial 514-2015 MTC/01.02). Recuperado de https://vlex.com.pe/vid/resolucion-ministerial-n-514-582043222

Ministerio de Transporte y Obras Públicas del Gobierno de la República del Ecuador. Recuperado de https://www.obraspublicas.gob.ec/\#

Ministry of Foreign Affairs of the People's Republic of China. (2018). China's Initiation of the Five Principles of Peaceful Co-Existence. Recuperado de http://www.fmprc.gov.cn/mfa eng/ziliao 665539/3602 665543/3604 665547/t18053.shtml

Monge, J. \& Yagüe Perales, R. (2016). El desarrollo turístico sostenible. Tren Crucero del Ecuador. Estudios y Perspectivas en Turismo, 25(1), 57-72. Recuperado de https://www.estudiosenturismo.com.ar/

Nieto, C. (2011). El ferrocarril en Colombia y la búsqueda de un país. Apuntes, 24(1), 6275. Recuperado de http://www.scielo.org.co/pdf/apun/v24n1/v24n1a05.pdf

Ochoa, R. (2018) ¿Cambio de ciclo o post-globalización? El impacto en América Latina. En A. Serbin. (Ed.), América Latina y el Caribe frente a un Nuevo Orden Mundial: Poder, globalización y respuestas regionales (pp. 107-122). Barcelona, España: Icaria. Recuperado https://www.dipublico.org/111380/america-latina-y-el-caribe-frente-al-nuevo- 


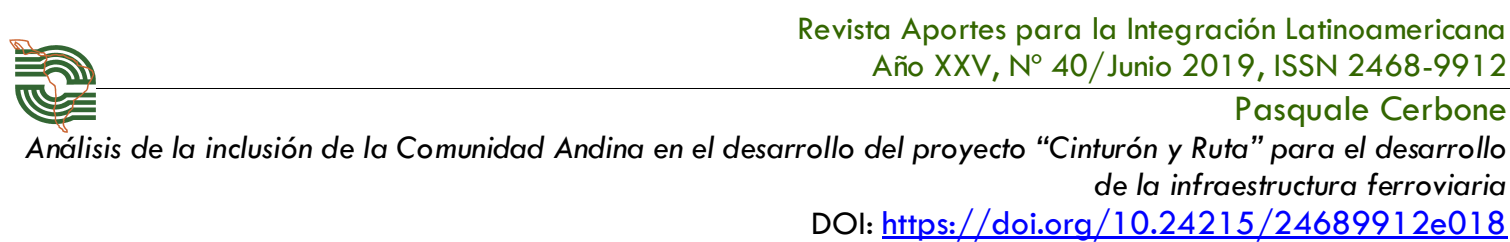

orden-mundial-poder-globalizacion-y-respuestas-regionales/

Padilla, M. (4 de Julio de 2018). China es el octavo socio de Bolivia en inversión extranjera. La Razón. Recuperado de http://www.larazon.com/suplementos/el financiero/ChinaoctavoBoliviainversionextranjera 029577042 $\underline{75 . h t m l}$

Pardo Fernández, A., Duverger Goyanes, J., Maynard Bermúdez, G. I., Izquierdo Hernández, A., Rojas Fernández, J. Monteserrín Puig, C. \& Ponce Sánchez, Y. (2005). Matriz de balance de fuerzas innovada. BAFI. Guantánamo: Facultad de Ciencias Médicas de Guantánamo. Recuperado de http://revinfodir.sld.cu/index.php/infodir/article/view/149/163

Pastrana Buelvas, E. \& Castro, R. (2018). Orden mundial y transición de poder en América Latina. Un nuevo ciclo para América Latina. En A. Serbin. (Ed.), América Latina y el Caribe frente a un Nuevo Orden Mundial: Poder, globalización y respuestas regionales (pp. 123-138). Barcelona, España: Icaria. Recuperado de https://www.dipublico.org/111380/americalatinayelcaribefrentealnuevoordenmundialpoderglobalizacion-y-respuestas-regionales/

Quirós, L. (2017). Reconfiguración política y gobernanza regional en América Latina ¿Hacia dónde va el regionalismo post-liberal? Revista Andina de Estudios Políticos, 7(2), 111-131. Recuperado de https://sociologiaenlaunjfsc.com/2018/02/05/revista-andina-deestudios-politicos-vol-7-num-2-2017/

Redacción Dinero. (12 de Marzo de 2017). El 90\% de las vías férreas están abandonadas y con máquinas de los años 50. Dinero. Recuperado https://www.dinero.com/economia/articulo/industria-de-los-ferrocarrilesencolombia/253000

Redacción Gestión. (6 de Diciembre de 2016). Perú cuenta con 13 proyectos ferroviarios por más de US\$26,776 millones, ¿cuáles son? Gestión. Recuperado de https://gestion.pe/economia/peru-cuenta-13-proyectos-ferroviarios-us-26-776-millonesson-122910

Rocha Pino, M. (2017). Los proyectos de integración megarregional de China: el caso de la iniciativa Cinturón y Ruta (CYR). Anuario Mexicano de Derecho Internacional, 17, 547589. http://dx.doi.org/10.22201/iij.24487872e.2017.17.11045

Rodríguez, M. (2017). One Belt, One Road: estado de desarrollo 2017 (Informe de la Oficina Económica Comercial de la Embajada de España en Pekín). Recuperado: https://www.icex.es/icex/es/navegacion-principal/todos-nuestros-servicios/informacion-demercados/estudiosdemercadosyotrosdocumentosdecomercioexterior/DOC2017723750.ht $\underline{\mathrm{ml}}$ 


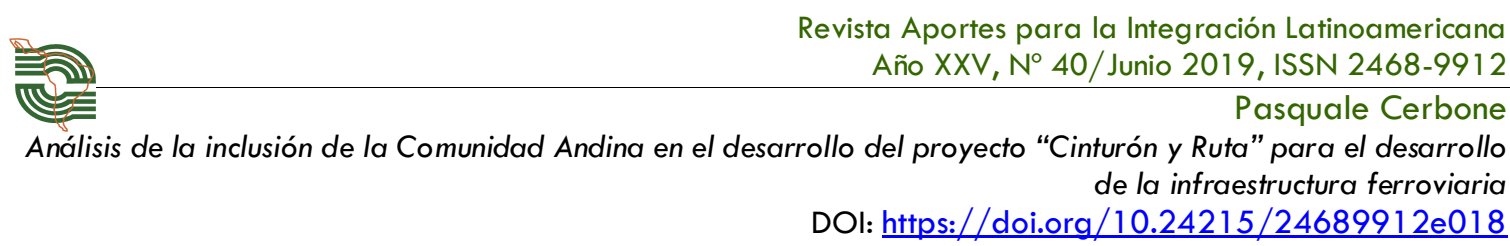

Secretaria Nacional de Planificación y Desarrollo. (2017). Proyecto K025 SENPLADES/INP-Estudio de prefactibilidad del tren de carga eléctrico del Ecuador. Quito, Ecuador. Recuperado de: https://www.planificacion.gob.ec/wpcontent/uploads/downloads/2019/03/Estudio-de-prefactibilidad-del-tren-de-carga-electricodel-Ecuador.pdf

Serbin, A. (2018). América Latina y el Caribe frente a un nuevo orden mundial: crisis de la globalización, reconfiguración global del poder y respuestas regionales. En A. Servin (Ed), América Latina y el Caribe frente a un Nuevo Orden Mundial: Poder, globalización y respuestas regionales (pp. 13-36). Argentina: Icaria CRIES Recuperado https://www.dipublico.org/111380/americalatinayelcaribefrentealnuevoordenmundialpoderglobalizacion-y-respuestas-regionales/

Servicio de Aeropuertos Bolivianos S.A. (s/d). Recuperado de http://www.sabsa.aero/

Transparency International. (2018). Corruption Perceptions Index 2017. Recuperado de https://www.transparency.org/news/feature/corruption perceptions index 2017

van Klaveren, A. (2018). El eterno retorno del regionalismo latinoamericano. Nueva Sociedad, (275), 62-72. Recuperado de https://nuso.org/articulo/el-eterno-retorno-delregionalismo-latinoamericano/

Velásquez-Castellanos, I. \& Pacheco Torrico, N. (Coords.) (2017). Un siglo de economía en Bolivia (1900-2015). La Paz, Bolivia: Konrad Adenauer Stiftung.

Wilmsmeier, G. (2007). Infraestructura y servicios de transporte ferroviario vinculados a las vías de navegación fluvial en América del Sur. Serie Recursos naturales e Infraestructura, (124), 1-76. Recuperado de https://www.cepal.org/es/publicaciones/6325infraestructura-servicios-transporte-ferroviario-vinculados-vias-navegacion

Wilson, J., \& Bayon, M. (2017). Fantastical materializations: Interoceanic infraestructures in the Ecuadorian Amazon. Environment and Planning D: Society and Space, 35, 836-854. https://doi.org/10.1177\%2F0263775817695102

Xu, Q., Shen, L., Jiang, Y., \& Jin, Z. (2017). Multimodal transport routing problem considering transshipment and accessibility: The case of the "One Belt One Road" Initiative, International Conference on Transportation Information and Safety, ICTIS. DOI. https://doi.org/10.1109/ICTIS.2017.8047881

Xu, W., Zhou , J., Yang, L., \& Li, L. (2018). The implication of high-speed rail for Chinese cities: Connectivity and accessibility. Transportation Research Part A, 116, 308-326. DOI: 10.1016/j.tra.2018.06.023 
Análisis de la inclusión de la Comunidad Andina en el desarrollo del proyecto "Cinturón y Ruta" para el desarrollo de la infraestructura ferroviaria DOI: https://doi.org/10.24215/24689912e018

Cerbone Pasquale: Lic. en Ciencias Políticas y Msc. En Relaciones Internacionales y Análisis de Escenario en la Universitá degli Studi di Napoli, Federico II (Italia). Doctorando en Marketing Político en la Universidad de Santiago de Compostela (España). Docente de Geopolítica en la Facultad de Ciencias Administrativas, para la Carrera de Negocios Internacionales e investigador en la Universidad UTE, con sede a Quito (Ecuador).

Fecha de recepción: 27-03-2019

Fecha de aceptación: 17-06-2019 